FEDERAL RESERVE BANK OF SAN FRANCISCO

WORKING PAPER SERIES

\title{
The Bond Premium in a DSGE Model with Long-Run Real and Nominal Risks
}

\author{
Glenn Rudebusch \\ Federal Reserve Bank of San Francisco \\ Eric Swanson \\ Federal Reserve Bank of San Francisco
}

March 2009

Working Paper 2008-31

http://www.frbsf.org/publications/economics/papers/2008/wp08-31bk.pdf

The views in this paper are solely the responsibility of the authors and should not be interpreted as reflecting the views of the Federal Reserve Bank of San Francisco or the Board of Governors of the Federal Reserve System. 


\title{
The Bond Premium in a DSGE Model with Long-Run Real and Nominal Risks*
}

\author{
Glenn D. Rudebusch ${ }^{\dagger} \quad$ Eric T. Swanson ${ }^{\ddagger}$ \\ March 2009, first draft August 2008
}

\begin{abstract}
The term premium on nominal long-term bonds in the standard dynamic stochastic general equilibrium (DSGE) model used in macroeconomics is far too small and stable relative to empirical measures obtained from the data - an example of the "bond premium puzzle." However, in models of endowment economies, researchers have been able to generate reasonable term premiums by assuming that investors have recursive Epstein-Zin preferences and face long-run economic risks. We show that introducing Epstein-Zin preferences into a canonical DSGE model can also produce a large and variable term premium without compromising the model's ability to fit key macroeconomic variables. Long-run real and nominal risks further improve the model's ability to fit the data with a lower level of household risk aversion.
\end{abstract}

${ }^{*}$ We are grateful for helpful comments and suggestions from John Campbell, Ivan Jaccard, Hagen Kim, Sharon Kozicki, Jean-Marc Natal, Monika Piazzesi, Martin Schneider, David Vestin, Moto Yogo, Stan Zin, participants at the NBER EFG Meeting, NBER Asset Pricing Meeting, the SED Meetings, SCE Meetings, Bank of Canada conference on Fixed Income Markets, National Bank of Belgium conference on Monetary and Financial Economics, DSGE Workshop at the Cleveland Fed, and seminar participants at the Kansas City Fed and University of Indiana. The views expressed in this paper are those of the authors and do not necessarily reflect the views of other individuals within the Federal Reserve System.

${ }^{\dagger}$ Federal Reserve Bank of San Francisco; http://www.frbsf.org/economists/grudebusch; Glenn.Rudebusch @sf.frb.org.

${ }^{\ddagger}$ Federal Reserve Bank of San Francisco; http://www.ericswanson.us; eric.swanson@sf.frb.org. 


\section{Introduction}

The term premium on long-term nominal bonds compensates investors for inflation and consumption risks over the lifetime of the bond. A large finance literature finds that these risk premiums are substantial and vary significantly over time (e.g., Campbell and Shiller, 1991, Cochrane and Piazzesi, 2005); however, the economic forces that can justify such large and variable term premiums are less clear. Piazzesi and Schneider (2006) provide some economic insight into the source of a large positive mean term premium in a consumption-based asset pricing model of an endowment economy. Their analysis relies on two crucial features: first, the structural assumption that investors have Epstein-Zin recursive utility preferences, ${ }^{1}$ and second, an estimated reduced-form process for the joint determination of consumption and inflation. With these two elements, they show that investors require a premium for holding nominal bonds because a positive inflation surprise lowers a bond's value and is associated with lower future consumption growth. In such a situation, bondholders' wealth decreases just as their marginal utility rises, so they require a premium to offset this risk. Using a similar structure - characterized by both Epstein-Zin preferences and reduced-form consumption and inflation empirics - Bansal and Shaliastovich (2007) also obtain significant time variation in the term premium.

An important shortcoming of such analyses is that they rely on reduced-form empirical correlations between consumption growth and inflation that have no direct structural foundation and may not be stable over time. For example, if the relative importance of technology shocks changes over time, then the reduced-form correlations may change. A more structural economic model of preferences and technology, such as the standard dynamic stochastic general equilibrium (DSGE) framework used in macroeconomics, can account for these changes and illuminate which features of the economy drive the term premium. In this paper, we undertake such a structual analysis.

Our paper also sheds light on whether the above authors' results in an endowment economy with Epstein-Zin investors carry over to the case of a general equilibrium, production economy. There is some reason to be skeptical in this regard. Although Wachter (2006) obtained

\footnotetext{
1 Early on, Kreps and Porteus (1978) established the theoretical framework for such recursive preferences, which were further developed by Epstein and Zin (1989) and Weil (1989).
} 
a significant mean term premium in an endowment economy using long-memory habit preferences (à la Campbell and Cochrane, 1999), Rudebusch and Swanson (2008) showed that such long-memory habits generated only a negligible term premium in a DSGE model. In particular, because households in a production economy can endogenously trade off labor and consumption, they are much better insulated from consumption risk than households in an endowment economy, who must consume whatever endowment they receive. In a production economy, when households are hit by a negative shock, they can compensate by increasing their labor supply and working more hours, which provides partial insurance against shocks to consumption. ${ }^{2}$ Households in an endowment economy do not have this opportunity, so the consumption cost of shocks is correspondingly greater, and risky assets thus carry a larger risk premium. Therefore, it is important to explore whether the endowment economy results with Epstein-Zin preferences also hold in a production economy.

We use a standard macroeconomic DSGE model to analyze the economic forces behind movements in long-term bond premiums. Relative to the equity premium, the long-term bond premium has received less attention in the literature, but is arguably even more important. From a real-world perspective, the value of long-term bonds outstanding in the U.S. (as in other countries) is far larger than the value of equities. Also, central banks around the world use the yield curve to measure expectations about monetary policy and inflation, so understanding movements in bond premiums is an important input for policy. The bond premium can also serve as a useful metric with which to assess model performance. For example, Boldrin, Christiano, and Fisher (2001) show that the presence of capital immobility in a two-sector DSGE model can account for the equity premium because it greatly increases the variance of the price of capital and its covariance with consumption; however, this mechanism cannot explain a long-term bond premium, which involves the valuation of a constant nominal coupon on a default-free government bond. More generally, the bond premium is closely related to the behavior of inflation and nominal rigidities, which are crucial and still unresolved aspects of the current generation of DSGE models. Finally, modeling the bond premium only requires a short-term

\footnotetext{
2 Jermann (1998), Lettau and Uhlig (2000), and Boldrin, Christiano, and Fisher (2001) also stress this difference between endowment and production economies in accounting for the equity premium. Our inability to generalize Wachter's (2006) results to a DSGE setting can be thought of as a failure of DSGE models with Campbell-Cochrane (1999) habits to generate a consumption process that is as volatile as we observe in the data. This is because Campbell-Cochrane households despise high-frequency variation in consumption, so endogenously generating a consumption process as volatile as the data requires enormous variation in prices, wages, or both.
} 
interest rate process, which is already included in standard DSGE models, while modeling the equity premium depends on uncertain specifications for dividends and leverage.

The underlying form of our DSGE model closely follows the standard specification of these models in the literature (e.g., Woodford, 2003, Christiano, Eichenbaum, and Evans, 2005, Smets and Wouters, 2003) and, notably, contains an important role for nominal rigidities in order to endogenously describe the behavior of inflation, short-term nominal interest rates, and long-term nominal bonds. We evaluate the model based on its ability to match both basic macroeconomic moments (e.g., the standard deviations of consumption and inflation) and basic bond pricing moments (e.g., the means and volatilities of the yield curve slope and bond excess holding period returns). In order to match the bond pricing facts, we augment the standard DSGE model in two ways. First, we assume that households in the model have Epstein-Zin preferences, so risk aversion can be modeled independently from the intertemporal elasticity of substitution. ${ }^{3}$ Such a separation allows the model to match risk premiums even in the face of the intertemporal substitution possibilities associated with a variable labor supply. Second, we assume that agents in the model face long-run economic risks, as in Bansal and Yaron (2004). ${ }^{4}$ However, because we are pricing a nominal asset, we consider not just long-run real risk, but also long-run nominal risk, in the sense that the central bank's long-run inflation objective may vary over time, as in Gürkaynak, Sack, and Swanson (2005). ${ }^{5}$

Together, these two key ingredients - Epstein-Zin preferences and long-run economic riskallow our model to replicate the bond pricing facts without compromising its ability to fit the macroeconomic facts. Intuitively, our model is identical to first order to standard macroeconomic DSGE representations because the first-order approximation to Epstein-Zin preferences is the same as the first-order approximation to standard expected utility preferences. Furthermore, the macroeconomic moments of the model are not very sensitive to the additional second- and higher-order terms introduced by Epstein-Zin preferences, while risk premiums are unaffected by first-order terms and completely determined by those second- and higher-order terms. Therefore,

\footnotetext{
3 Van Binsbergen, Fernández-Villaverde, Koijen, and Rubio-Ramírez (2008) also price bonds in a DSGE model with Epstein-Zin preferences, although their model treats inflation as an exogenous stochastic process and thus suffers from some of the same drawbacks as Piazzesi and Schneider (2006) and Bansal and Shaliastovich (2007).

4 Bansal and Yaron (2004) show that uncertainty about the economy's long-run growth prospects can play an important role in generating sizable equity risk premiums.

${ }^{5}$ Gürkaynak, Sack, and Swanson (2005) find that the excess sensitivity of long-term bond yields to macroeconomic announcements appears to be due to financial markets expecting some degree of pass-through from near-term inflation to the long-term inflation outlook.
} 
by varying the Epstein-Zin risk-aversion parameter while holding the other parameters of the model constant, we are able to fit the asset pricing facts without compromising the model's ability to fit the macroeconomic data.

Our analysis has implications for both the macroeconomics and finance literatures. For macroeconomics, our results suggest a path to transform the standard DSGE model into a complete description of the economy. As a theoretical matter, asset prices and the macroeconomy are inextricably linked; indeed, as emphasized by Cochrane (2007), asset markets are the mechanism by which capital is allocated efficiently across firms and by which consumption and investment are allocated efficiently across time and states of nature. Therefore, any correctly specified DSGE model must be capable of matching interest rates and other asset prices as well as consumption and inflation. For finance, our analysis can illuminate the earlier reduced-form results with a structural economic interpretation. We also suggest a resolution to a long-standing puzzle in the bond-pricing literature (Backus, Gregory, and Zin, 1989, and Den Haan, 1995); namely, why does the yield curve slope upward? If interest rates are low during a recession, then bond prices should be high when consumption is low; as a result, long-term bonds should carry an insurance-like, negative risk premium and the yield curve should - counterfactually - slope downward. In our DSGE model, the yield curve slopes upward because technology shocks cause inflation to rise persistently when consumption falls, so long-term nominal bonds lose rather than gain value in recessions, implying a positive risk premium. More generally, any shock that causes inflation to move persistently and inversely to output, including a markup shock or an oil price shock, will tend to imply such a positive term premium.

The remainder of the paper proceeds as follows. Section 2 generalizes a standard DSGE model to the case of Epstein-Zin preferences. Section 3 presents results for this model and shows how it is able to match the term premium without impairing the model's ability to fit macroeconomic variables. Section 4 introduces a model with enhanced long-run economic risks, which improves the model's overall fit to the data. Section 5 concludes. A brief technical appendix provides additional details of how general DSGE models can be extended to the case of Epstein-Zin preferences and solved. 


\section{A DSGE Model with Epstein-Zin Preferences}

In this section, we generalize the simple, stylized DSGE model of Woodford (2003) to the case of Epstein-Zin preferences. We show how to price long-term nominal bonds in this model and present a variety of measures of the term premium and long-term bond risk.

\subsection{Epstein-Zin Preferences}

It is standard practice in macroeconomics to assume that a representative household chooses state-contingent plans for consumption, $c$, and labor, $l$, so as to maximize expected utility:

$$
\max E_{0} \sum_{t=0}^{\infty} \beta^{t} u\left(c_{t}, l_{t}\right)
$$

subject to an asset accumulation equation, where $\beta \in(0,1)$ is the household's discount factor and the period utility kernel $u\left(c_{t}, l_{t}\right)$ is twice-differentiable, concave, increasing in $c$, and decreasing in $l$. The maximand in equation (1) can be expressed in first-order recursive form as:

$$
V_{t} \equiv u\left(c_{t}, l_{t}\right)+\beta E_{t} V_{t+1},
$$

where the household's state-contingent plans at time $t$ are chosen so as to maximize $V_{t}$.

In this paper, we follow the finance literature and generalize (2) to an Epstein-Zin specification:

$$
V_{t} \equiv u\left(c_{t}, l_{t}\right)+\beta\left(E_{t} V_{t+1}^{1-\alpha}\right)^{1 /(1-\alpha)},
$$

where the parameter $\alpha$ can take on any real value. ${ }^{6}$ If $u \geq 0$ everywhere, then the proof of Theorem 3.1 in Epstein and Zin (1989) shows that there exists a solution $V$ to (3) with $V \geq 0$. If $u \leq 0$ everywhere, then it is natural to let $V \leq 0$ and reformulate the recursion as:

$$
V_{t} \equiv u\left(c_{t}, l_{t}\right)-\beta\left[E_{t}\left(-V_{t+1}\right)^{1-\alpha}\right]^{1 /(1-\alpha)} .
$$

The proof in Epstein and Zin (1989) also demonstrates the existence of a solution $V$ to (4) with $V \leq 0$ in this case. ${ }^{7}$ When $\alpha=0$, both (3) and (4) reduce to the standard case of expected

\footnotetext{
${ }^{6}$ The case $\alpha=1$ corresponds to $V_{t}=u\left(c_{t}, l_{t}\right)+\beta \exp \left(E_{t} \log V_{t+1}\right)$ for the case $u \geq 0$, and $V_{t}=u\left(c_{t}, l_{t}\right)-$ $\beta \exp \left[E_{t} \log \left(-V_{t+1}\right)\right]$ for $u \leq 0$.

7 We exclude the case where $u$ is sometimes positive and sometimes negative, although for local approximations around a deterministic steady state with infinitesimal uncertainty, this case does not present any particular difficulties.
} 
utility (2). When $u \geq 0$ everywhere, higher (lower) values of $\alpha$ correspond to greater (lesser) degrees of risk aversion. When $u \leq 0$ everywhere, the opposite is true: higher (lower) values of $\alpha$ correspond to lesser (greater) degrees of risk aversion.

Note that, traditionally, Epstein-Zin preferences over consumption streams have been written as:

$$
\widetilde{V}_{t} \equiv\left[c_{t}^{\rho}+\beta\left(E_{t} \widetilde{V}_{t+1}^{\widetilde{\alpha}}\right)^{\rho / \widetilde{\alpha}}\right]^{1 / \rho},
$$

but by setting $V_{t}=\widetilde{V}_{t}^{\rho}$ and $\alpha=1-\widetilde{\alpha} / \rho$, this can be seen to correspond to (3). Moreover, the form (3) has the advantage that it allows us to consider standard DSGE utility kernels involving both labor and inelastic intertemporal substitution $(\rho<0)$, which the form $(5)$ cannot easily handle.

The key advantage of using Epstein-Zin utility (3) is that it breaks the equivalence between the inverse of the intertemporal elasticity of substitution and the coefficient of relative risk aversion that has long been noted in the literature regarding expected utility (2) - see, e.g., Mehra and Prescott (1985) and Hall (1988). In (3), the intertemporal elasticity of substitution over deterministic consumption paths is exactly the same as in (2), but now the household's risk aversion to uncertain lotteries over $V_{t+1}$ can be amplified by the additional parameter $\alpha$, a feature which is crucial for allowing us to fit both the asset pricing and macroeconomic facts below. ${ }^{8}$

We now turn to the utility kernel $u$. For simplicity, we adopt the usual DSGE specification (e.g., Woodford, 2003):

$$
u\left(c_{t}, l_{t}\right) \equiv \frac{c_{t}^{1-\gamma}}{1-\gamma}-\chi_{0} \frac{l_{t}^{1+\chi}}{1+\chi},
$$

which allows for tractable modeling of nominal wage as well as price rigidities - an essential ingredient of many models in this literature. If $\gamma>1$, then (6) is everywhere negative and $V$ is defined by (4). If $\gamma \leq 1$, then there are two main approaches to ensure that the utility kernel $u$ is everywhere positive. The first is to add a constant:

$$
u\left(c_{t}, l_{t}\right) \equiv \frac{c_{t}^{1-\gamma}}{1-\gamma}-\chi_{0} \frac{l_{t}^{1+\chi}}{1+\chi}+\frac{\chi_{0} \bar{l}^{1+\chi}}{1+\chi}
$$

where $\bar{l}$ denotes the household's time endowment. Note, however, that additive shifts of the

\footnotetext{
${ }^{8}$ Indeed, the linearization or log-linearization of (3) is exactly the same as that of (2), which turns out to be very useful for matching the model to macroeconomic variables, since models with (2) are already known to be able to fit macroeconomic quantities reasonably well. We will return to this point in Section 3 , below.
} 
utility kernel, as in (7), are nonneutral and affect the household's attitude towards risk, except for the special case of expected utility, $\alpha=0$. (This will become apparent when we derive the household's stochastic pricing kernel, below.) The second approach is to use (6) but impose that there is some subsistence level $\underline{c} \geq 0$ for consumption below which households cannot go. By setting $\underline{c}$ high enough, we can ensure that $u$ is positive over the range of admissible values for $c$ and $l$. Of these two approaches, we will generally opt for the latter when we consider the case $\gamma<1$ in the estimation below.

\subsection{The Household's Optimization Problem}

We now turn to the representative household's optimization problem under Epstein-Zin preferences. We assume that households are representative and choose state-contingent consumption and labor plans so as to maximize (3) subject to an intertemporal-flow budget constraint, specified below. We will solve the household's optimization problem as a Lagrange problem with the states of nature explicitly specified. To that end, let $s^{0} \in S_{0}$ denote the initial state of the economy at time 0 , let $s_{t} \in S$ denote the realizations of the shocks that hit the economy in period $t$, and let $s^{t} \equiv\left\{s^{t-1}, s_{t}\right\} \in S_{0} \times S^{t}$ denote the initial state and history of all shocks up through time $t$. We define $s_{t-1}^{t}$ to be the projection of the history $s^{t}$ onto its first $t$ components; that is, $s_{t-1}^{t}$ is the history $s^{t}$ as it would have been viewed at time $t-1$, before time- $t$ shocks have been realized.

Households have access to an asset whose price is given by $p_{t, s^{t}}>0$ in each period $t$ and state of the world $s^{t}$. In each period $t$, households choose the quantity of consumption $c_{t, s^{t}}$, labor $l_{t, s^{t}}$, and asset holdings $a_{t, s^{t}}$ that will carry through to the next period, subject to a constraint that the household's asset holdings $a_{t, s^{t}}$ are always greater than some lower bound $\underline{a} \ll 0$, which does not bind in equilibrium but rules out Ponzi schemes. Households are price takers in consumption, asset, and labor markets, and face a price per unit of consumption of $P_{t, s^{t}}$, and nominal wage rate $w_{t, s^{t}}$. Households also own an aliquot share of firms and receive a per-period lump-sum transfer from firms in the amount $d_{t, s^{t}}$. The household's flow budget constraint is thus:

$$
p_{t, s^{t}} a_{t, s^{t}}+P_{t, s^{t}} c_{t, s^{t}}=w_{t, s^{t}} l_{t, s^{t}}+d_{t, s^{t}}+p_{t, s^{t}} a_{t-1, s_{t-1}^{t}}
$$

The household's optimization problem is to choose a sequence of vector-valued functions, 
$\left[c_{t}\left(s^{t}\right), l_{t}\left(s^{t}\right), a_{t}\left(s^{t}\right)\right]: S_{0} \times S^{t} \rightarrow[\underline{c}, \infty] \times[0, \bar{l}] \times[\underline{a}, \infty)$, so as to maximize (3) subject to the sequence of budget constraints (8). For clarity in what follows, we assume that $s^{0}$ and $s_{t}$ can take on only a finite number of possible values (i.e., $S_{0}$ and $S$ have finite support), and we let $\pi_{s^{\tau} \mid s^{t}}, \tau \geq t \geq 0$, denote the probability of realizing state $s^{\tau}$ at time $\tau$ conditional on being in state $s^{t}$ at time $t$.

The household's optimization problem can be formulated as a Lagrangean, where the household chooses state-contingent plans for consumption, labor, and asset holdings, $\left(c_{t, s^{t}}, l_{t, s^{t}}, a_{t, s^{t}}\right)$, that maximize $V_{0}$ subject to the infinite sequence of state-contingent constraints (3) and (8), that is, maximize:

$$
\begin{aligned}
\mathcal{L} \equiv & V_{0, s^{0}}-\sum_{t=0}^{\infty} \sum_{s^{t}} \mu_{t, s^{t}}\left\{V_{t, s^{t}}-u\left(c_{t, s^{t}}, l_{t, s^{t}}\right)-\beta\left(\sum_{s^{t+1}} \pi_{s^{t+1} \mid s^{t}} V_{t+1, s^{t+1}}^{1-\alpha}\right)^{1 /(1-\alpha)}\right\}- \\
& \sum_{t=0}^{\infty} \sum_{s^{t}} \lambda_{t, s^{t}}\left\{p_{t, s^{t}} a_{t, s^{t}}+P_{t, s^{t}} c_{t, s^{t}}-w_{t, s^{t}} l_{t, s^{t}}-d_{t, s^{t}}-p_{t, s^{t}} a_{t-1, s_{t-1}^{t}}\right\} .
\end{aligned}
$$

The household's first-order conditions for (9) are then:

$$
\begin{array}{lll}
\frac{\partial \mathcal{L}}{\partial c_{t, s^{t}}}: & \left.\mu_{t, s^{t}} u_{1}\right|_{\left(c_{t, s^{t}}, l_{t, s^{t}}\right)}=P_{t, s^{t}} \lambda_{t, s^{t}} \\
\frac{\partial \mathcal{L}}{\partial l_{t, s^{t}}}: & -\left.\mu_{t, s^{t}} u_{2}\right|_{\left(c_{t, s^{t}}, l_{t, s^{t}}\right)}=w_{t, s^{t}} \lambda_{t, s^{t}} \\
\frac{\partial \mathcal{L}}{\partial a_{t, s^{t}}}: & \lambda_{t, s^{t}} p_{t, s^{t}}=\sum_{s^{t+1} \supseteq s^{t}} \lambda_{t+1, s^{t+1}} p_{t+1, s^{t+1}}, \\
\frac{\partial \mathcal{L}}{\partial V_{t, s^{t}}}: & \mu_{t, s^{t}}=\beta \pi_{s^{t} \mid s_{t-1}^{t}} \mu_{t-1, s_{t-1}^{t}}\left(\sum_{\widetilde{s}^{t} \supseteq s_{t-1}^{t}} \pi_{\widetilde{s}^{t} \mid s_{t-1}^{t}} V_{t, \widetilde{s}^{t}}^{1-\alpha}\right)^{\alpha /(1-\alpha)} V_{t, s^{t}}^{-\alpha} \quad \mu_{0, s^{0}}=1 .
\end{array}
$$

Letting $\left(1+r_{t+1, s^{t+1}}\right) \equiv p_{t+1, s^{t+1}} / p_{t, s^{t}}$, the gross rate of return on the asset, making substitutions, and defining the stationary Lagrange multipliers $\widetilde{\lambda}_{t, s^{t}} \equiv \beta^{-t} \pi_{s^{t} \mid s^{0}}^{-1} \lambda_{t, s^{t}}$ and $\widetilde{\mu}_{t, s^{t}} \equiv \beta^{-t} \pi_{s^{t} \mid s^{0}}^{-1} \mu_{t, s^{t}}$, these become:

$$
\begin{array}{lll}
\frac{\partial \mathcal{L}}{\partial c_{t, s^{t}}}: & \left.\widetilde{\mu}_{t, s^{t}} u_{1}\right|_{\left(c_{t, s}, l_{t, s}\right)}=P_{t, s^{t}} \widetilde{\lambda}_{t, s^{t}} \\
\frac{\partial \mathcal{L}}{\partial l_{t, s^{t}}}: & -\left.\widetilde{\mu}_{t, s^{t}} u_{2}\right|_{\left(c_{t, s}, l_{t, s}\right)}=w_{t, s^{t}} \widetilde{\lambda}_{t, s^{t}} \\
\frac{\partial \mathcal{L}}{\partial a_{t, s^{t}}}: & \widetilde{\lambda}_{t, s^{t}}=\beta E_{t, s^{t}} \widetilde{\lambda}_{t+1, s^{t+1}}\left(1+r_{\left.t+1, s^{t+1}\right)}\right. \\
\frac{\partial \mathcal{L}}{\partial V_{t, s^{t}}}: & \widetilde{\mu}_{t, s^{t}}=\widetilde{\mu}_{t-1, s_{t-1}^{t}}\left(E_{t-1, s_{t-1}^{t}} V_{t, \widetilde{s}^{t}}^{1-\alpha}\right)^{\alpha /(1-\alpha)} V_{t, s^{t}}^{-\alpha} ; \quad \widetilde{\mu}_{0, s^{0}}=1 .
\end{array}
$$


These first-order conditions are very similar to the expected utility case except for the introduction of the additional Lagrange multipliers $\widetilde{\mu}_{t, s}$, which translate utils at time $t$ into utils at time 0 , allowing for the "twisting" of the value function by $1-\alpha$ that takes place at each time $1,2, \ldots, t$. Note that in the expected utility case, $\widetilde{\mu}_{t, s^{t}}=1$ for every $t$ and $s^{t}$, and equations (10) through (13) reduce to the standard optimality conditions. Similarly, linearizing (10) through (13) separates out $\widetilde{\mu}_{t, s^{t}}$ and causes $\alpha$ to drop out, so to first order, (10) through (13) are identical to the expected utility case.

Substituting out for $\widetilde{\lambda}_{t, s^{t}}$ and $\widetilde{\mu}_{t, s^{t}}$ in (10) through (13), we get the household's intratemporal and intertemporal (Euler) optimality conditions:

$$
\begin{aligned}
& \frac{-\left.u_{2}\right|_{\left(c_{t, s}, l_{t, s}\right)}}{\left.u_{1}\right|_{\left(c_{t, s}, l_{t, s}\right)}}=\frac{w_{t, s^{t}}}{P_{t, s^{t}}} \\
& \left.u_{1}\right|_{\left(c_{t, s^{t}}, l_{t, s^{t}}\right)}=\left.\beta E_{t, s^{t}}\left(E_{t, s^{t}} V_{t+1, s^{t+1}}^{1-\alpha}\right)^{\alpha /(1-\alpha)} V_{t+1, s^{t+1}}^{-\alpha} u_{1}\right|_{\left(c_{t+1, s^{t+1}}, l_{t+1, s^{t+1}}\right)}\left(1+r_{t+1, s^{t+1}}\right) P_{t, s^{t}} / P_{t+1, s^{t+1}} .
\end{aligned}
$$

Finally, let $p_{t, s^{t}}^{s^{\tau}}, t \leq \tau$, denote the price at time $t$ in state $s^{t}$ of a state-contingent bond that pays one dollar at time $\tau$ in state $s^{\tau}$ and 0 otherwise. If we insert this state-contingent security into the household's optimization problem, we see that, for $t<\tau$ :

$$
p_{t, s^{t}}^{s^{\tau}}=\beta E_{t, s^{t}}\left(E_{t, s^{t}} V_{t+1, s^{t+1}}^{1-\alpha}\right)^{\alpha /(1-\alpha)} V_{t+1, s^{t+1}}^{-\alpha} \frac{\left.u_{1}\right|_{\left(c_{t+1, s^{t+1}, l_{t+1, s} t+1}\right)}}{\left.u_{1}\right|_{\left(c_{t, s}, l_{t, s}\right)}} \frac{P_{t, s^{t}}}{P_{t+1, s^{t+1}}} p_{t+1, s^{t+1}}^{s^{\tau}} \text {. }
$$

That is, the household's (nominal) stochastic discount factor at time $t$ in state $s^{t}$ for stochastic payoffs at time $t+1$ is given by:

$$
m_{t, s^{t}, t+1, s^{t+1}} \equiv\left(\frac{V_{t+1, s^{t+1}}}{\left(E_{t, s^{t}} V_{t+1, s^{t+1}}^{1-\alpha}\right)^{1 /(1-\alpha)}}\right)^{-\alpha} \frac{\left.\left.\beta u_{1}\right|_{\left(c_{t+1, s} t+1, l_{t+1, s} t+1\right.}\right)}{\left.u_{1}\right|_{\left(c_{t, s}, l_{t, s}\right)}} \frac{P_{t, s^{t}}}{P_{t+1, s^{t+1}}} .
$$

Despite the twisting of the value function by $1-\alpha$, the price $p_{t, s^{t}}^{s^{\tau}}$ nevertheless satisfies the standard relationship,

$$
\begin{aligned}
p_{t, s^{t}}^{s^{\tau}} & =E_{t, s^{t}} m_{t, s^{t}, t+1, s^{t+1}} m_{t+1, s^{t+1}, t+2, s^{t+2}} p_{t+2, s^{t+2}}^{s^{\tau}} \\
& =E_{t, s^{t}} m_{t, s^{t}, t+1, s^{t+1}} m_{t+1, s^{t+1}, t+2, s^{t+2}} \cdots m_{\tau-1, s^{\tau-1}, \tau, s^{\tau}}
\end{aligned}
$$

and the asset pricing equation (14) is linear in the future state-contingent payoffs, so that we can price any compound security by summing over the prices of its individual constituent state-contingent payoffs. 


\subsection{The Firm's Optimization Problem}

To model nominal rigidities, we assume that the economy contains a continuum of monopolistically competitive intermediate goods firms indexed by $f \in[0,1]$ that set prices according to Calvo contracts and hire labor from households in a competitive labor market. Firms have identical Cobb-Douglas production functions:

$$
y_{t}(f)=A_{t} \bar{k}^{(1-\eta)} l_{t}(f)^{\eta}
$$

where $\bar{k}$ is a fixed, firm-specific capital stock and $A_{t}$ denotes an aggregate technology shock that affects all firms. ${ }^{9}$ We have suppressed the explicit state-dependence of the variables in this equation and in the remainder of the paper to ease the notational burden. The technology shock $A_{t}$ follows an exogenous $\mathrm{AR}(1)$ process:

$$
\log A_{t}=\rho_{A} \log A_{t-1}+\varepsilon_{t}^{A}
$$

where $\varepsilon_{t}^{A}$ denotes an independently and identically distributed (i.i.d.) aggregate technology shock with mean zero and variance $\sigma_{A}^{2}$.

Firms set prices according to Calvo contracts that expire with probability $1-\xi$ each period. When the Calvo contract expires, the firm is free to reset its price as it chooses, and we denote the price that the firm $f$ sets in period $t$ by $p_{t}(f)$. There is no indexation, so the price $p_{t}(f)$ is fixed over the life of the contract. In each period $\tau \geq t$ that the contract remains in effect, the firm must supply whatever output is demanded at the contract price $p_{t}(f)$, hiring labor $l_{\tau}(f)$ from households at the market wage $w_{\tau}$.

Firms are collectively owned by households and distribute profits and losses back to households each period. When a firm's price contract expires, the firm chooses the new contract price $p_{t}(f)$ to maximize the value to shareholders of the firm's cash flows over the lifetime of the contract (equivalently, the firm chooses a state-contingent plan for prices that maximizes the value of the firm to shareholders). That is, the firm maximizes:

$$
E_{t} \sum_{j=0}^{\infty} \xi^{j} m_{t, t+j}\left[p_{t}(f) y_{t+j}(f)-w_{t+j} l_{t+j}(f)\right]
$$

9 Woodford (2003), Altig, Christiano, Eichenbaum, and Lindé (2004), and others have emphasized the importance of firm-specific fixed factors for generating a level of inflation persistence that is consistent with the data. Firm-specific capital stocks also help to match the term premium as well as the persistence of inflation. 
where $m_{t, t+j}$ is the representative household's stochastic discount factor from period $t$ to $t+j$.

The output of each intermediate firm $f$ is purchased by a perfectly competitive final goods sector that aggregates the continuum of intermediate goods into a single final good using a CES production technology:

$$
Y_{t}=\left[\int_{0}^{1} y_{t}(f)^{1 /(1+\theta)} d f\right]^{1+\theta} .
$$

Each intermediate firm $f$ thus faces a downward-sloping demand curve for its product:

$$
y_{t}(f)=\left(\frac{p_{t}(f)}{P_{t}}\right)^{-(1+\theta) / \theta} Y_{t}
$$

where $P_{t}$ is the CES aggregate price per unit of the final good:

$$
P_{t} \equiv\left[\int_{0}^{1} p_{t}(f)^{-1 / \theta} d f\right]^{-\theta}
$$

Differentiating (18) with respect to $p_{t}(f)$ yields the standard optimality condition for the firm's price:

$$
p_{t}(f)=\frac{(1+\theta) E_{t} \sum_{j=0}^{\infty} \xi^{j} m_{t, t+j} m c_{t+j}(f) y_{t+j}(f)}{E_{t} \sum_{j=0}^{\infty} \xi^{j} m_{t, t+j} y_{t+j}(f)} .
$$

where $m c_{t}(f)$ denotes the marginal cost for firm $f$ at time $t$ :

$$
m c_{t}(f) \equiv \frac{w_{t} l_{t}(f)}{\eta y_{t}(f)}
$$

\subsection{Aggregate Resource Constraints and the Government}

To aggregate up from firm-level variables to aggregate quantities, it is useful to define crosssectional price dispersion, $\Delta_{t}$ :

$$
\Delta_{t}^{1 / \eta} \equiv(1-\xi) \sum_{j=0}^{\infty} \xi^{j} p_{t-j}(f)^{-(1+\theta) / \theta \eta}
$$

where the occurrence of the parameter $\eta$ in the exponent is due to the firm-specificity of capital. We define $L_{t}$, the aggregate quantity of labor demanded by firms, as:

$$
L_{t} \equiv \int_{0}^{1} l_{t}(f) d f
$$

Then $L_{t}$ satisfies:

$$
Y_{t}=\Delta_{t}^{-1} A_{t} \bar{K}^{1-\eta} L_{t}^{\eta},
$$


where $\bar{K}=\bar{k}$ is the capital stock. Equilibrium in the labor market requires that $L_{t}=l_{t}$, labor demand equals the aggregate labor supplied by the representative households.

In order to study the effects of fiscal shocks, we assume that there is a government sector in the model that levies lump-sum taxes $G_{t}$ on households and destroys the resources it collects. Government consumption follows an exogenous $\mathrm{AR}(1)$ process:

$$
\log G_{t}=\rho_{G} \log G_{t-1}+\varepsilon_{t}^{G}
$$

where $\varepsilon_{t}^{G}$ denotes an i.i.d. government consumption shock with mean zero and variance $\sigma_{G}^{2}$.

Although agents cannot invest in physical capital in this version of the model, we do assume that an amount $\delta \bar{K}$ of output each period is devoted to maintaining the fixed capital stock. Thus, the aggregate resource constraint implies that

$$
Y_{t}=C_{t}+\delta \bar{K}+G_{t}
$$

where $C_{t}=c_{t}$, the consumption of the representative household.

Finally, there is a monetary authority in the economy which sets the one-period continuouslycompounded nominal interest rate $i_{t}$ according to a Taylor-type policy rule:

$$
i_{t}=\rho_{i} i_{t-1}+\left(1-\rho_{i}\right)\left[\log (1 / \beta)+\log \bar{\pi}_{t}+g_{y}\left(Y_{t}-\bar{Y}\right) / \bar{Y}+g_{\pi}\left(\log \bar{\pi}_{t}-\log \pi^{*}\right)\right]+\varepsilon_{t}^{i},
$$

where $\log (1 / \beta)$ is the steady-state real interest rate in the model, $\bar{Y}$ denotes the steady-state level of output, $\pi^{*}$ denotes the steady-state rate of inflation, $\varepsilon_{t}^{i}$ denotes an i.i.d. stochastic monetary policy shock with mean zero and variance $\sigma_{i}^{2}$, and $\rho_{i}, g_{y}$, and $g_{\pi}$ are parameters. ${ }^{10}$ The variable $\bar{\pi}_{t}$ denotes a geometric moving average of inflation:

$$
\bar{\pi}_{t}=\theta_{\pi} \bar{\pi}_{t-1}+\left(1-\theta_{\pi}\right) \pi_{t}
$$

where current-period inflation $\pi_{t} \equiv \log \left(P_{t} / P_{t-1}\right)$ and we set $\theta_{\pi}=0.7$ so that the geometric average in (30) has an effective duration of about four quarters, which is typical in estimates of the Taylor rule. ${ }^{11}$

\footnotetext{
10 In equation (29) (and equation (29) only), we express $i_{t}, \pi_{t}$, and $1 / \beta$ in annualized terms, so that the coefficients $g_{\pi}$ and $g_{y}$ correspond directly to the estimates in the empirical literature. We also follow the literature by assuming an "inertial" policy rule with i.i.d. policy shocks, although there are a variety of reasons to be dissatisfied with the assumption of $\mathrm{AR}(1)$ processes for all stochastic disturbances except the one asociated with short-term interest rates. Indeed, Rudebusch (2002, 2006) and Carrillo, Fève, and Matheron (2007) provide strong evidence that an alternative policy specification with serially correlated shocks and little gradual adjustment is more consistent with the dynamic behavior of nominal interest rates.

11 Including the usual four-quarter moving average of inflation in the policy rule adds three lags $\left(\pi_{t-1}, \pi_{t-2}\right.$, and $\left.\pi_{t-3}\right)$ as state variables, while our geometric average adds only one lag $\left(\bar{\pi}_{t-1}\right)$. All results are very similar for either specification.
} 


\subsection{Long-Term Bonds and the Term Premium}

The price of any asset in the model economy must satisfy the standard stochastic discounting relationship in which the household's stochastic discount factor is used to value the statecontingent payoffs of the asset in period $t+1$. For example, the price of a default-free $n$-period zero-coupon bond that pays one dollar at maturity satisfies:

$$
p_{t}^{(n)}=\mathrm{E}_{t}\left[m_{t+1} p_{t+1}^{(n-1)}\right]
$$

where $m_{t+1} \equiv m_{t, t+1}, p_{t}^{(n)}$ denotes the price of the bond at time $t$, and $p_{t}^{(0)} \equiv 1$, i.e., the time- $t$ price of one dollar delivered at time $t$ is one dollar. The continuously-compounded yield to maturity on the $n$-period zero-coupon bond is defined to be:

$$
i_{t}^{(n)} \equiv-\frac{1}{n} \log p_{t}^{(n)}
$$

In the U.S. data, the benchmark long-term bond is the ten-year Treasury note. Thus, we wish to model the term premium on a bond with a duration of about ten years. Computationally, it is inconvenient to work with a zero-coupon bond that has more than a few periods to maturity; instead, it is much easier to work with an infinitely-lived consol-style bond that has a timeinvariant or time-symmetric structure. ${ }^{12}$ Thus, we assume that households in the model can buy and sell a long-term default-free nominal consol which pays a geometrically declining coupon in every period in perpetuity. The nominal consol's price per one dollar of coupon in period $t$, which we denote by $\widetilde{p}_{t}^{(n)}$, then satisfies:

$$
\widetilde{p}_{t}^{(n)}=1+\delta_{c} \mathrm{E}_{t} m_{t+1} \widetilde{p}_{t+1}^{(n)}
$$

where $\delta_{c}$ is the rate of decay of the coupon on the consol. By choosing an appropriate value for $\delta_{c}$, we can thus model prices of a bond of any desired Macaulay duration or maturity $n$, such as the ten-year maturity that serves as our zero-coupon benchmark in the data. ${ }^{13}$ Finally, the

\footnotetext{
12 We have also verified that all of our results continue to hold with zero-coupon bonds as well as the consol. However, solving the model with zero-coupon bonds takes much (eight to ten times) longer than solving the model with the consol, because solving for the 40-quarter zero-coupon bond price essentially requires solving for zero-coupon bond prices of all maturities from one to 40 quarters. The consol can be solved by adding just one first-order recursive equation to the model.

13 As $\delta_{c}$ approaches 0 , the consol behaves more like cash-a zero-period zero-coupon bond. As $\delta_{c}$ approaches 1 , the consol approaches a traditional consol with a fixed (nondepreciating) nominal coupon, which, under our baseline parameter values below, has a duration of about 25 years. By setting $\delta_{c}>1$, the duration of the consol can be made even longer.
} 
continuously-compounded yield to maturity on the consol, $\widetilde{\imath}_{t}^{(n)}$, is given by:

$$
\widetilde{\imath}_{t}^{(n)} \equiv \log \left(\frac{\delta_{c} \widetilde{p}_{t}^{(n)}}{\widetilde{p}_{t}^{(n)}-1}\right) .
$$

Note that even though the nominal bond in our model is default-free, it is still risky in the sense that its price can covary with the household's marginal utility of consumption. For example, when inflation is expected to be higher in the future, then the price of the bond generally falls, because households discount its future nominal coupons more heavily. If times of high inflation are correlated with times of low output (as is the case for technology shocks in the model), then households regard the nominal bond as being very risky, because it loses value at exactly those times when the household values consumption the most. Alternatively, if inflation is not very correlated with output and consumption, then the bond is correspondingly less risky. In the former case, we would expect the bond to carry a substantial risk premium (its price would be lower than the risk-neutral price), while in the latter case we would expect the risk premium to be smaller.

In the literature, the risk premium or term premium on a long-term bond is typically expressed as the difference between the yield on the bond and the unobserved risk-neutral yield for that same bond. To define the term premium in our model, then, we first define the risk-neutral price of the consol, $\widehat{p}_{t}^{(n)}$ :

$$
\widehat{p}_{t}^{(n)} \equiv \mathrm{E}_{t} \sum_{j=0}^{\infty} e^{-i_{t, t+j}} \delta_{c}^{j},
$$

where $i_{t, t+j} \equiv \sum_{n=0}^{j} i_{n}$. Equation (35) is the expected present discounted value of the coupons of the consol, where the discounting is performed using the risk-free rate rather than the household's stochastic discount factor. Equivalently, equation (35) can be expressed in first-order recursive form as:

$$
\widehat{p}_{t}^{(n)}=1+\delta_{c} e^{-i_{t}} \mathrm{E}_{t} \widehat{p}_{t+1}^{(n)}
$$

which directly parallels (33). The implied term premium on the consol is then given by:

$$
\psi_{t}^{(n)} \equiv \log \left(\frac{\delta_{c} \widetilde{p}_{t}^{(n)}}{\widetilde{p}_{t}^{(n)}-1}\right)-\log \left(\frac{\delta_{c} \widehat{p}_{t}^{(n)}}{\widehat{p}_{t}^{(n)}-1}\right),
$$

which is the difference between the observed yield to maturity on the consol and the risk-neutral yield to maturity. For a given set of structural parameters of the model, we will choose $\delta_{c}$ so 
that the bond has a Macaulay duration of $n=40$ quarters, and we will multiply equation (37) by 400 in order to report the term premium in units of annualized percentage points rather than logs.

The term premium in equation (37) can also be expressed more directly in terms of the stochastic discount factor, which can be useful for gaining intuition about how the term premium is related to the various economic shocks driving our DSGE model. First, use (33) and (36) to write the difference between the consol price and the risk-neutral consol price as:

$$
\begin{aligned}
\widetilde{p}_{t}^{(n)}-\widehat{p}_{t}^{(n)} & =\delta_{c}\left(\mathrm{E}_{t} m_{t+1} \widetilde{p}_{t+1}^{(n)}-\mathrm{E}_{t} m_{t+1} E_{t} \widehat{p}_{t+1}^{(n)}\right), \\
& =\delta_{c}\left[\operatorname{Cov}_{t}\left(m_{t+1}, \widetilde{p}_{t+1}^{(n)}\right)+\mathrm{E}_{t} m_{t+1} \mathrm{E}_{t}\left(\widetilde{p}_{t+1}^{(n)}-\widehat{p}_{t+1}^{(n)}\right)\right], \\
& =\delta_{c}\left[\operatorname{Cov}_{t}\left(m_{t+1}, \widetilde{p}_{t+1}^{(n)}\right)+e_{t}^{-i_{t}} \mathrm{E}_{t}\left(\widetilde{p}_{t+1}^{(n)}-\widehat{p}_{t+1}^{(n)}\right)\right], \\
& =E_{t} \sum_{j=0}^{\infty} e^{-i_{t, t+j}} \delta_{c}^{t+j+1} \operatorname{Cov}_{t+j}\left(m_{t+j+1}, \widetilde{p}_{t+j+1}^{(n)}\right),
\end{aligned}
$$

Equation (38) makes it clear that, even though the bond price depends only on the one-periodahead covariance between the stochastic discount factor and next period's bond price, the term premium depends on this covariance over the entire lifetime of the bond. ${ }^{14}$

Of course, the term premium is usually written as the difference between the yield on the long-term bond and the risk-neutral yield on that bond. From (37),

$$
\begin{aligned}
\psi_{t}^{(n)} & =\log \left(1-1 / \widehat{p}_{t}^{(n)}\right)-\log \left(1-1 / \widehat{p}_{t}^{(n)}\right), \\
& \approx \frac{-1}{\bar{p}_{t}^{(n) 2}}\left(\widetilde{p}_{t}^{(n)}-\widehat{p}_{t}^{(n)}\right), \\
& =\frac{-1}{\bar{p}_{t}^{(n) 2}} E_{t} \sum_{j=0}^{\infty} e^{-i_{t, t+j}} \delta_{c}^{t+j+1} \operatorname{Cov}_{t+j}\left(m_{t+j+1}, \widetilde{p}_{t+j+1}^{(n)}\right),
\end{aligned}
$$

where $\bar{p}_{t}^{(n)}$ denotes the nonstochastic steady-state bond price. ${ }^{15}$ Intuitively, the term premium is larger the more negative is the covariance between the stochastic discount factor and the price of the bond over the lifetime of the bond.

\footnotetext{
14 An exactly analogous expression holds for the case of a zero-coupon bond.

15 The first-order approximation on the second line of (39) is useful for gaining intuition and is a good approximation because the bond prices $\widehat{p}_{t}^{(n)}$ and $\widetilde{p}_{t}^{(n)}$ are about 40 for the parameterizations of the model we consider below. However, when we solve for the term premium in the model numerically, our solution will include the second- and third-order as well as the first-order terms.
} 


\subsection{Alternative Measures of Long-Term Bond Risk}

Although the term premium is the cleanest conceptual measure of the riskiness of long-term bonds, it is not directly observed in the data and must be inferred using term structure models or other methods. Accordingly, the literature has also focused on two other directly observed empirical measures that are closely related to the term premium: the slope of the yield curve and the excess return to holding the long-term bond for one period relative to the one-period short rate.

The slope of the yield curve is simply the difference between the yield to maturity on the long-term bond and the one-period risk-free rate, $i_{t}$. The slope is an imperfect measure of the riskiness of the long-term bond because it can vary in response to shocks even if all investors in the model are risk-neutral. However, on average, the slope of the yield curve equals the term premium, and the volatility of the slope provides us with a noisy measure of the volatility of the term premium.

A second measure of the riskiness of long-term bonds is the excess one-period holding return - that is, the return to holding the bond for one period less the one-period risk-free rate. For the case of an $n$-period zero-coupon bond, this excess return is given by:

$$
x_{t}^{(n)} \equiv \frac{p_{t}^{(n-1)}}{p_{t-1}^{(n)}}-e^{i_{t-1}} .
$$

The first term on the right-hand side of (40) is the gross return to holding the bond and the second term is the gross one-period risk-free return. For the case of the consol in our model, the excess holding period return is a bit more complicated, since the consol pays a coupon in period $t-1$ and then depreciates in value by the factor $\delta_{c}$, so the excess holding period return is given by:

$$
\widetilde{x}_{t}^{(n)} \equiv \frac{\delta_{c} \widetilde{p}_{t}^{(n)}+e^{i_{t-1}}}{\widetilde{p}_{t-1}^{(n)}}-e^{i_{t-1}} .
$$

Again, the first term on the right-hand side of (41) is the gross return to holding the consol and includes the one-dollar coupon in period $t-1$ that can be invested in the one-period security. As with the yield curve slope, the excess returns in (40) and (41) are imperfect measures of the term premium because they would vary in response to shocks even if investors were risk-neutral. However, the mean and standard deviation of the excess holding period return provide popular measures of the average term premium and the volatility of the term premium. 


\subsection{Model Solution Method}

A technical issue in solving the model above arises from its relatively large number of state variables: $A_{t-1}, G_{t-1}, i_{t-1}, \Delta_{t-1}, \bar{\pi}_{t-1}$, and the three shocks, $\varepsilon_{t}^{A}, \varepsilon_{t}^{G}$, and $\varepsilon_{t}^{i}$, make a total of eight. ${ }^{16}$ Because of this high dimensionality, discretization and projection methods are computationally infeasible, so we solve the model using the standard macroeconomic technique of approximation around the nonstochastic steady state - so-called perturbation methods. However, a first-order approximation of the model (i.e., a linearization or log-linearization) eliminates the term premium entirely, because equations (33) and (36) are identical to first order. A second-order approximation to the solution of the model produces a term premium that is nonzero but constant (a weighted sum of the variances $\sigma_{A}^{2}, \sigma_{G}^{2}$, and $\sigma_{i}^{2}$ ). Since our interest in this paper is not just in the level of the term premium but also in its volatility and variation over time, we compute a third-order approximate solution to the model around the nonstochastic steady state using the algorithm of Swanson, Anderson, and Levin (2006). For the baseline model above with eight state variables, a third-order accurate solution can be computed in just a few minutes on a standard laptop computer, and for the more complicated specifications we consider below with long-run risks, a third-order solution can be computed in 20 or 30 minutes. Additional details of this solution method are provided in Swanson, Anderson, and Levin (2006) and Rudebusch, Sack, and Swanson (2007).

Once we have computed an approximate solution to the model, we compare the model and the data using a standard set of macroeconomic and financial moments, such as the standard deviations of consumption, labor, and other variables, and the means and standard deviations of the term premium and the alternative measures of long-term bond risk described above. One method of computing these moments is by simulation, but this method is slow and, for a nonlinear model, the simulations can sometimes diverge to infinity. We thus compute these moments in closed form, using perturbation methods. In particular, we compute the unconditional standard deviations and unconditional means of the variables of the model to second order. ${ }^{17}$ For the term premium, the unconditional standard deviation is zero to second order,

\footnotetext{
16 The number of state variables can be reduced a bit by noting that $G_{t}$ and $A_{t}$ are sufficient to incorporate all of the information from $G_{t-1}, A_{t-1}, \varepsilon_{t}^{G}$, and $\varepsilon_{t}^{A}$, but the basic point remains valid, namely, that the number of state variables in the model is large from a computational point of view.

17 To compute the standard deviations of the variables to second order, we compute a fourth-order accurate solution to the unconditional covariance matrix of the variables and then take the square root along the diagonal. Note that a third-order accurate solution for $X$ and $Y$ is sufficient to compute the product $E[X Y]$ to fourth
} 
so we compute the unconditional standard deviation of the term premium to third order. This method yields results that are extremely close to those that arise from simulation, while at the same time being quicker and more numerically robust.

\section{Comparing the Epstein-Zin DSGE Model to the Data}

We now investigate whether the standard DSGE model, extended to the case of Epstein-Zin preferences as developed in the previous section, is consistent with the most basic features of the macroeconomic and financial market data. We first investigate the behavior of the model under a baseline set of parameter values and then vary those parameters to find the best possible fit of the model to the data.

\subsection{Model Parameterization}

The baseline parameter values that we use for our simple New Keynesian model are reported in Table 1 and are fairly standard in the literature (e.g., Levin, Onatski, Williams, and Williams, 2005). We set the household's discount factor, $\beta$, to .99 per quarter, implying a steady-state real interest rate of 4.02 percent per year. We set households' utility curvature with respect to consumption, $\gamma$, to 2 , implying an intertemporal elasticity of substitution (IES) in consumption of 0.5, which is consistent with estimates in the micro literature (e.g., Vissing-Jorgensen, 2002), but we will also estimate this parameter below. Households' utility curvature with respect to labor, $\chi$, is set to 1.5 , implying a Frisch elasticity of $2 / 3$, which is also in line with estimates from the microeconomics literature (e.g., Pistaferri, 2003). We discuss the parameter $\alpha$ and its relationship to the coefficient of relative risk aversion in Section 3.2.

We set firms' output elasticity with respect to labor, $\eta$, to .7, firms' steady-state markup, $\theta$, to .2 (implying a price-elasticity of demand of 6), and the Calvo frequency of price adjustment, $\xi$, to .75 (implying an average price contract duration of four quarters), all of which are standard in the literature. We set the steady-state capital-output ratio in the model to 2.5 (where output is annualized), and the capital depreciation rate to 2 percent per quarter (implying a steadystate investment-output ratio of 20 percent). Government purchases are assumed to consume

order, when $X$ and $Y$ have zero mean (as in a covariance). 
Table 1

Baseline Parameter Values for the Simple DSGE Model

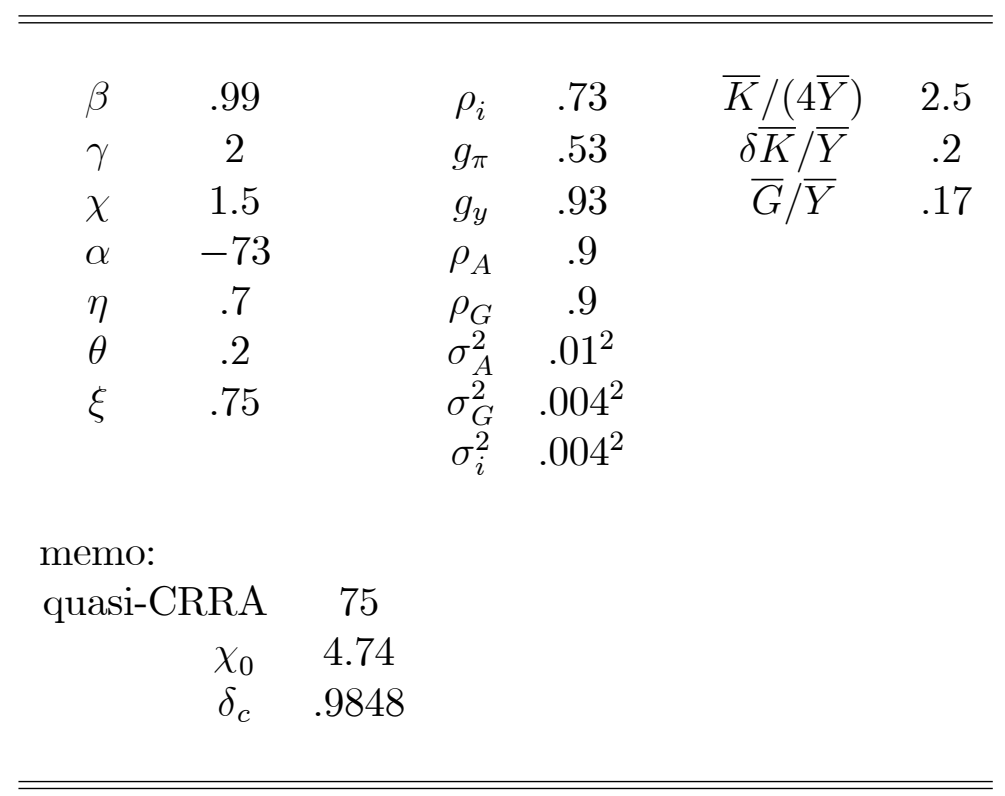

17 percent of output in the steady state. The monetary policy rule coefficients are taken from Rudebusch (2002) and are also typical of those in the literature. The shock persistences $\rho_{A}$ and $\rho_{G}$ are set to .9 , as is common, and the shock variances $\sigma_{A}^{2}, \sigma_{G}^{2}$, and $\sigma_{i}^{2}$ are set to $.01^{2}, .004^{2}$, and $.004^{2}$, respectively, consistent with typical estimates in the literature. Finally, the parameter $\chi_{0}$ is chosen to normalize the steady-state quantity of labor to unity and the parameter $\delta_{c}$ is chosen to set the Macaulay duration of the consol in the model to ten years, as discussed above.

\subsection{The Coefficient of Relative Risk Aversion}

The degree of risk aversion exhibited by households in our model is a crucial but difficult-tomeasure element of our analysis. In previous studies of Epstein-Zin preferences in an endowment economy setting, the household's optimization problem is typically homothetic - that is, the quantity of consumption demanded in each period depends linearly on the household's initial wealth (e.g., this is true in a model with fixed labor, $u\left(c_{t}, l_{t}\right)=c_{t}^{1-\gamma} /(1-\gamma)$, and with shocks that have a multiplicative effect on wealth). As a result, the household's value-to-go $V_{t}$ in each period is equal to a constant (function of parameters) times $W_{t}^{1-\gamma}$, where $W_{t}$ denotes beginningof-period household wealth. In that case, the expectation in $(3)$ is over $W_{t+1}^{(1-\alpha)(1-\gamma)}$, and it is common to refer to $1-(1-\alpha)(1-\gamma)$ as the household's coefficient of relative risk aversion with respect to gambles over next-period wealth. 
In contrast, the value function for the household's optimization problem in our DSGE model is much more complicated. First, the utility kernel is not homothetic due to the presence of labor; ${ }^{18}$ second, the shocks in the model do not enter multiplicatively with respect to wealth; and third, the household's true wealth includes human as well as physical capital. For these reasons, the household's value function is not simply separable in wealth - in fact, the household's value function has multiple state variables and, as discussed by Kihlstrom and Mirman (1974), it is difficult to define risk aversion when there is more than one good or more than one state variable. As a result, there is no standard or even unambiguous quantitative measure of risk aversion in our model. ${ }^{19}$

In order to compare our model and results to the endowment economy literature, we thus report the quasi-CRRA, $1-(1-\alpha)(1-\gamma)$. The interpretation of this coefficient is that, if labor in our model were held fixed, and if utility were homothetic, and if all the shocks in the model were multiplicative with respect to wealth, then the CRRA in the model would be the quasi-CRRA that we report. In the baseline parameterization of our model given in Table 1, the Epstein-Zin coefficient $\alpha$ is set to -73 , and $\gamma$ is 2 , which implies a quasi-CRRA of 75 . This may seem like a high baseline value, but we will also estimate a high value in the "best fit" exercise below, and it will be helpful for gaining intuition for our results to have a baseline quasi-CRRA that is similarly high.

We emphasize, however, that there are many reasons why this quasi-CRRA is not a very good measure of households' true attitudes toward risk in our model. For example, if we consider gambles over current-period consumption, $c_{t}$, holding future consumption and current and future labor fixed, the household behaves as if its CRRA were simply $\gamma$, the same as in the expected utility case and far less than the quasi-CRRA of $75 .^{20}$ That is, if we think of laboratory experiments using small rewards as affecting only current-period consumption and not future labor supply or consumption, then households in our model would exhibit a risk

\footnotetext{
${ }^{18}$ For the household's preferences to be homothetic, the quantity of consumption and leisure demanded in each period must scale linearly with wealth. This is not the case for any standard utility kernel with consumption and leisure because leisure is bounded above by the household's time endowment. In particular, nonhomotheticity is not specific to the additively separable utility kernel (6).

19 We do know from Epstein and Zin (1989) that, for $u\left(c_{t}, l_{t}\right) \geq 0$ everywhere, higher values of $\alpha$ correspond to greater risk aversion. The issue here is that we have no easy way to quantify the degree of risk aversion in our model in a way that one could compare to the empirical literature.

20 That is, letting $c_{t}=c^{*}+\sigma \varepsilon$, the Arrow-Pratt coefficient is $-c_{t}\left(\partial^{2} V_{t} / \partial \sigma^{2}\right) /\left(\partial V_{t} / \partial c^{*}\right)=\gamma$. Kreps and Porteus (1978) also noted that gambles over current period consumption are viewed the same by a household with generalized recursive preferences as they are by a household with expected utility preferences.
} 
aversion of $\gamma=2$ in those experiments. For analogous gambles over next-period consumption, $c_{t+1}$, the household behaves as if its CRRA were $\gamma+\alpha \bar{c}^{1-\gamma} / \bar{V}$, which is about 25 percent higher than $\gamma$ under our baseline parameterization, but still much less than the quasi-CRRA. ${ }^{21}$ Even for gambles over steady-state consumption, $\bar{c}$ (that is, the household's level of consumption in every period, holding labor fixed), the household behaves as if its CRRA were $\gamma+\frac{\alpha \beta}{1-\beta} \bar{c}^{1-\gamma} / \bar{V}$, which is about 55, a high number yet still substantially less than the quasi-CRRA. Thus, the quasi-CRRA is at best only a very rough measure of households' attitudes toward risk in the model.

Even taking the quasi-CRRA in our model at face value, Barillas, Hansen, and Sargent (2008) show that low household risk aversion together with a moderate degree of uncertainty about the economic environment can be isomorphic to an Epstein-Zin specification with a risk aversion parameter of 50 to 100 or more. In other words, one of the reasons our simple DSGE model requires such a high quasi-CRRA to fit the empirical risk premiums is that households in our model have absolutely perfect knowledge about all of the equations of the model, the model's parameter values, and so on. Thus, the quantity of risk in our model is much smaller than in the U.S. economy and, as a result, the household's aversion to risk in our model must be correspondingly higher in order to fit the data. As Barillas, Hansen, and Sargent show, what looks like a high quasi-CRRA in our model with no parameter or model uncertainty can just as well be due to a low degree of true household risk aversion and a moderate degree of household uncertainty about the parameters and equations of the model.

In addition, Malloy, Moskowitz, and Vissing-Jorgensen (2008) show that the consumption of stockholders is more volatile than the consumption of nonstockholders. As a result, the required level of risk aversion in a representative-agent model like ours is higher than the level of risk aversion that would be required in a model that recognized that asset-holders have more variable consumption than households that do not hold assets. In other words, our simple, representativeagent DSGE model again may understate the true quantity of risk that bondholders in the U.S. economy face. Since our model understates the quantity of risk faced by U.S. households, it requires a higher degree of risk aversion in order to match the risk premiums in the data.

Taken together, these observations suggest that our baseline value for the quasi-CRRA in

21 In our model, $\frac{\bar{C}^{1-\gamma} /(1-\gamma)}{\bar{V}}=(1-\beta) /\left(1-\frac{1-\gamma}{1+\chi} \frac{\eta}{1+\theta} \frac{\bar{Y}}{\bar{C}}\right) \simeq .0073$, where bars denote steady-state values. 
the model, and the high value that we will estimate below, are not unreasonable and could be reduced greatly if one were to increase the uncertainty and risks faced by bondholders in the model to more realistic levels.

\subsection{Model Results}

We report various model-implied moments in Table 2, along with the corresponding empirical moments for quarterly U.S. data from 1960 to 2007. The first set of rows reports a set of basic macroeconomic moments that the model should be able to match, while the second set of rows reports a set of basic financial moments. ${ }^{22}$ Additional information about the model moments and parameter values are reported in the last two sets of rows of the table.

The empirical moments in the first column of Table 2 are relatively standard and were computed as follows: consumption, $C$, is real personal consumption expenditures from the U.S. national income and product accounts, labor, $L$, is total hours of production workers from the Bureau of Labor Statistics (BLS), and the real wage, $w^{r}$, is total wages and salaries of production workers from the BLS divided by total production worker hours and deflated by the GDP price index. Standard deviations were computed for logarithmic deviations of each series from a Hodrick-Prescott trend and reported in percentage points. Standard deviations for inflation, interest rates, and the term premium were computed for the raw series rather than for deviations from trend. Inflation, $\pi$, is the annualized rate of change in the quarterly GDP price index from the Bureau of Economic Analysis. The short-term nominal interest rate, $i$, is the end-of-month federal funds rate from the Federal Reserve Board, reported in annualized percentage points. The short-term real interest rate, $r$, is the short-term nominal interest rate less the realized quarterly inflation rate at an annual rate. The ten-year zero-coupon bond yield, $i^{(40)}$, is the end-of-month ten-year zero-coupon bond yield taken from Gurkaynak, Sack, and Wright (2007). The term premium on the ten-year zero-coupon bond, $\psi^{(40)}$, is the term premium computed by Kim and Wright (2005), in annualized percentage points. ${ }^{23}$ The yield

\footnotetext{
${ }^{22}$ We omit output from the macro moments because our simple DSGE model has fixed capital and investment, so output and consumption behave very similarly. The standard deviation of the long-term bond yield, $i^{(40)}$, has some elements of both a "macro" and a "finance" moment, but we will classify it as a macro moment for the purposes of the table and this discussion.

${ }^{23} \mathrm{Kim}$ and Wright (2005) use an arbitrage-free, three-latent-factor affine model of the term structure to compute the term premium. Alternative measures of the term premium using a wide variety of methods produce qualitatively similar results in terms of the overall magnitude and variability - see Rudebusch, Sack, and Swanson (2007) for a detailed discussion and comparison of several methods.
} 
curve slope and one-period excess holding return are calculated from the data above and are reported in annualized percentage points.

The second column of Table 2 reports results for the baseline version of our model with expected utility preferences (that is, all parameters are the same as in Table 1 , except that $\alpha=0$, which implies expected utility preferences for the household). The model does a reasonable job of matching the basic macroeconomic moments in the first seven rows of the table -indeed, this is one of the main reasons these models have become so widely used in macroeconomics. However, the term premium implied by the expected utility version of the model is both too small in magnitude - the model implies a term premium of one basis point - and far too stable, with an unconditional standard deviation less than one-tenth of one basis point. This basic finding of a term premium that is too small and far too stable relative to the data is extremely robust with respect to wide variation of the model's parameters (see Rudebusch and Swanson, 2008, for additional discussion and sensitivity analysis).

The third column of Table 2 reports results from the baseline parameterization of the model with Epstein-Zin preferences and a quasi-CRRA of $75(\alpha=-73)$. Note that the model fits all of the macroeconomic variables just as well as the expected utility version of the model: that is, even for relatively high levels of risk aversion, the dynamics of the macroeconomic variables implied by the model are largely unchanged, a finding that has also been noted by Tallarini (2000) and Backus, Routledge, and Zin (2007). This is a straightforward implication of two features of the model: first, the linearization or log-linearization of Epstein-Zin preferences (3) is exactly the same as that of standard expected utility preferences (2), so to first order, these two utility specifications are the same; and second, the shocks that we consider in the model and which are standard in macroeconomics have standard deviations of only about one percent or less, so a linear approximation to the model is typically very accurate. ${ }^{24}$

For asset prices, however, the implications of the Epstein-Zin and expected utility versions of the model are very different, since risk premia in the model are entirely determined by secondand higher-order terms. With Epstein-Zin preferences, the mean term premium is 43.8 basis

\footnotetext{
${ }^{24}$ As the magnitude of $\alpha$ increases, second-order terms in the model become relatively more important for the macroeconomic variables. Yet even for the case $\alpha=-73$, second-order terms do not have a very large effect on the macroeconomic moments in the second column of Table 2. Intuitively, this is because $V$ is both "twisted" and "untwisted" by the factor $(1-\alpha)$, so that much of the curvature that $\alpha$ introduces into the model is effectively neutralized. As a result, the parameter $\alpha$ only affects the macro variables in the model through its effect on uncertainty, precautionary motives, and the like, and this has only a small effect on the unconditional moments we report in Table 2.
} 
Table 2

Empirical and Model-Based Unconditional Moments

\begin{tabular}{|c|c|c|c|c|}
\hline $\begin{array}{c}\text { Unconditional } \\
\text { Moment }\end{array}$ & $\begin{array}{l}\text { U.S. Data, } \\
1961-2007\end{array}$ & $\begin{array}{l}\text { Model with } \\
\text { Expected } \\
\text { Utility } \\
\text { Preferences }\end{array}$ & $\begin{array}{l}\text { Model with } \\
\text { Epstein- } \\
\text { Zin } \\
\text { Preferences }\end{array}$ & $\begin{array}{l}\text { Model with } \\
\text { EZ } \\
\text { Preferences } \\
\text { (best fit) }\end{array}$ \\
\hline $\operatorname{sd}[C]$ & 1.19 & 1.40 & 1.46 & 2.12 \\
\hline $\operatorname{sd}[L]$ & 1.71 & 2.48 & 2.50 & 1.89 \\
\hline $\operatorname{sd}\left[w^{r}\right]$ & 0.82 & 2.02 & 2.02 & 2.02 \\
\hline $\operatorname{sd}[\pi]$ & 2.52 & 2.22 & 2.30 & 2.96 \\
\hline $\operatorname{sd}[i]$ & 2.71 & 1.86 & 1.93 & 2.65 \\
\hline $\operatorname{sd}[r]$ & 2.30 & 1.89 & 1.95 & 2.06 \\
\hline $\operatorname{sd}\left[i^{(40)}\right]$ & 2.41 & 0.52 & 0.57 & 1.17 \\
\hline $\operatorname{mean}\left[\psi^{(40)}\right]$ & 1.06 & .010 & .438 & 1.06 \\
\hline $\operatorname{sd}\left[\psi^{(40)}\right]$ & 0.54 & .000 & .053 & .162 \\
\hline $\operatorname{mean}\left[i^{(40)}-i\right]$ & 1.43 & -.038 & .390 & 0.95 \\
\hline $\operatorname{sd}\left[i^{(40)}-i\right]$ & 1.33 & 1.41 & 1.43 & 1.59 \\
\hline $\operatorname{mean}\left[x^{(40)}\right]$ & 1.76 & .010 & .431 & 1.04 \\
\hline $\operatorname{sd}\left[x^{(40)}\right]$ & 23.43 & 6.52 & 6.87 & 10.77 \\
\hline \multicolumn{5}{|l|}{ distance to: } \\
\hline macro moments & & 6.63 & 6.30 & 4.13 \\
\hline finance moments & & 9.48 & 6.22 & 2.56 \\
\hline all moments & & 16.11 & 12.53 & 6.68 \\
\hline \multicolumn{5}{|l|}{ memo: } \\
\hline quasi-CRRA & & 2 & 75 & 90 \\
\hline IES & & 0.5 & 0.5 & 0.5 \\
\hline$\chi$ & & 1.5 & 1.5 & 1.7 \\
\hline$\xi$ & & .75 & .75 & .7 \\
\hline$\rho_{A}$ & & 0.9 & 0.9 & 0.95 \\
\hline$\sigma_{A}$ & & .01 & .01 & .007 \\
\hline
\end{tabular}

All variables are quarterly values expressed in percent. Inflation, interest rates, the term premium $(\psi)$, and excess holding period returns $(x)$ are expressed at an annual rate. 
points - almost fifty times higher than under expected utility — and the standard deviation of the term premium is $5.3 \mathrm{bp}$, compared to less than $0.1 \mathrm{bp}$ for expected utility. ${ }^{25}$ The fit of the model to the yield curve slope and excess holding period return show similarly marked improvements.

Figure 1 graphically illustrates the effects of increasing the quasi-CRRA in the model by plotting the mean term premium $\left(\psi^{(40)}\right)$ as a function of the quasi-CRRA, holding all the other parameters of the model fixed at their baseline values. As the quasi-CRRA increases, the mean term premium rises steadily, so that essentially any level of the term premium can be attained by making households sufficiently risk-averse. This is not the case for expected utility preferences - the dotted line in the figure - because increasing the quasi-CRRA in that version of the model simultaneously decreases the intertemporal elasticity of substitution (the remaining parameters of the model are held fixed at their baseline values), and hence dampens the volatility of consumption in the model at the same time that it increases risk aversion. The net result is a maximum term premium of about 5 basis points, far less than the value in the data. Thus, separating risk aversion from the intertemporal elasticity of substitution is crucial for matching asset prices in the model.

The last column of Table 2 reports results from the "best fit" parameterization of the model with Epstein-Zin preferences, where we search over a wide range of values to find the parameterization that provides the closest joint fit of the model to both the macroeconomic and financial moments in the data. The computational time required to solve the model for any given set of parameter values is about 20 minutes, so it is generally infeasible to estimate all of the parameters of the model using maximum likelihood or Bayesian methods. Instead, we search over a range of values for the six parameters listed at the bottom of Table 2 that are among the most interesting and important for the term premium - namely, the quasi-CRRA, IES, $\chi, \xi, \rho_{A}$, and $\sigma_{A}$ - to find the best fit to the macroeconomic and financial moments in Table $2 .{ }^{26}$ We define

25 The mean and standard deviation of the term premium for a ten-year zero-coupon bond in the model are similar: the term premium has a mean of $40.3 \mathrm{bp}$ and an unconditional standard deviation of $2.5 \mathrm{bp}$. These numbers are a few basis points less than for the ten-year-duration consol, but still far larger than we have been able to obtain with standard or habit-based expected utility specifications (see, e.g., Rudebusch and Swanson, 2008). For the "best fit" parameterization of the model (the final column of Table 2), the corresponding numbers are a mean term premium of $86.5 \mathrm{bp}$ and standard deviation of $11.0 \mathrm{bp}$ for the 10-year zero-coupon bond.

${ }^{26}$ We conducted the search over the following sets of parameter values: quasi-CRRA $\in\{1,15,30,45,60,75,90\}$, IES $\in\{.5, .7, .9,1.1,1.3,1.5\}, \chi \in\{.5, .8,1.1,1.3,1.5,1.7,1.9,2.2,2.5\}, \xi \in\{.65, .7, .75, .8\}, \rho_{A} \in\{.9, .95\}$, and $\sigma_{A} \in\{.003, .004, .005, .006, .007, .008, .009, .01, .015, .02\}$. These sets were chosen to encompass a wide range of estimates in the literature. The parameter $\sigma_{A}$ can be varied at little computational cost, and the other parameters were distributed over a four-processor computer to reduce the overall computation time. 
the "best fit" to be the set of parameters that matches the equally-weighted sum of squared deviations from the thirteen moments in the first column of Table 2 as closely as possible (with one exception: we divide the standard deviation of the excess holding period return $x^{(40)}$ by 10 in order to give it roughly as much weight as the other moments in the column). ${ }^{27}$ The distance between the model and the empirical macro moments, finance moments, and both sets of moments together are reported in the third set of rows in the table, above the parameter values.

The best-fitting parameter values are reported at the bottom of the last column of Table 2 . These imply a mean term premium of about 106 basis points and a standard deviation of the term premium of 16.2 basis points, a much better fit than the baseline model. To achieve this fit, the estimation procedure picks high values for the quasi-CRRA, 90, and technology shock persistence, $\rho_{A}=.95$, and a low value for the IES, 0.5. All else equal, a high value for the quasi-CRRA helps the model to fit the financial moments in the data, and the low value for the IES helps to make real interest rates relatively more volatile and consumption relatively less volatile, both of which help to fit the macro moments in the table. With these extreme values for the quasi-CRRA, IES, and $\rho_{A}$, holding the standard deviation of the technology shock fixed at its baseline value would result in macroeconomic moments that are too volatile relative to the data, so the estimation chooses a lower standard deviation, $\sigma_{A}=.007$. The values for $\chi$ and $\xi$ are intermediate and well within the range of estimates in the literature.

\subsection{The Importance of Technology Shocks for the Term Premium}

We can gain insight into what features of the model are the most important for the term premium by examining the model's impulse responses to shocks. The first column of Figure 2 reports the responses of consumption, inflation, the long-term bond price, and the term premium in the model to a positive one-standard-deviation shock to technology, using the "best fit" parameterization from Table 2. The second and third columns report analogous impulse responses for one-standard-deviation shocks to government spending and monetary policy, respectively. ${ }^{28}$ These impulse responses demonstrate that the correlations between consumption,

\footnotetext{
27 Minimizing the equal-weighted distance to these thirteen moments provides us with a consistent estimator of our parameters, though it is not efficient.

28 These impulse responses are computed using the methods described in Rudebusch, Sack, and Swanson (2007). For consumption, inflation, and the long-term bond price, the first-order terms are dominant and
} 
inflation, and the long-term bond price depend on the type of structural shock.

Over the period 1952-2005, Piazzesi and Schneider (2006) find that a surprise increase in U.S. inflation - which lowers the value of nominal bonds - was typically followed by lower consumption going forward. This relationship implies that long-term nominal bonds lose value precisely when households desire consumption the most, resulting in a positive term premium (cf. equation (39)). In the first column of Figure 2, we can see that a technology shock in our structural model also has this feature: that is, inflation falls (rises) while the long-term bond price and future consumption both rise (fall). In contrast to technology shocks, government spending and monetary policy shocks in our model imply a correlation between inflation and consumption that is exactly the opposite: inflation, consumption, and long-term bond prices all fall simultaneously in response to the shock. Thus, the relationship between inflation and consumption depends on the distribution of the underlying shocks that are driving the economy, and the reduced-form inflation-consumption correlation that Piazzesi and Schneider estimate suggests that technology-type shocks predominated over their sample.

While technology shocks are also the most important driver of fluctuations in the macroeconomic variables of our DSGE model, the contribution of technology shocks to the model's term premium is even more crucial. As can be seen in Figure 2, all three shocks imply a negative covariance between the stochastic discount factor and the long-term bond price, and hence a positive term premium, but that covariance is both much larger and much longer-lasting for the technology shock. (This is primarily driven by the large and long-lasting effect that the technology shock has on inflation in the model, which in turn has a large effect on the long-term bond price.) As a result, the technology shock is far more important for the term premium than are the other two shocks, since its impact on the sum of the covariances in equation (39) is so much larger. Thus, in our standard DSGE model as well as in Piazzesi and Schneider (2006), technology shocks and the negative correlation between inflation and consumption that they generate are crucial for matching the term premium.

This observation provides an answer to a bond-pricing puzzle that dates back to Backus, Gregory, and Zin (1989) and Den Haan (1995): namely, why does the yield curve slope upward? According to the traditional line of thinking, if interest rates are low in a recession (when provide a very good approximation, so only those (linear) terms are plotted. For the term premium, the impulse response is zero to first and second order, so the third-order terms are dominant and are plotted in the figure. 
consumption is low), then long-term bond prices should be high in a recession and hence longterm bonds should carry an insurance-like, negative risk premium; that is, the yield curve should slope downward rather than upward. In our New Keynesian DSGE model, a technology shock causes inflation to rise persistently at the same time that consumption falls, so long-term nominal bonds lose value rather than gain value in recessions, as long as those recessions are driven by technology shocks. Thus, our model resolves the puzzle by appealing to the behavior of inflation following a technology shock in standard New Keynesian DSGE models. ${ }^{29}$ More generally, any shock that causes inflation to move persistently and inversely to output, such as a technology shock, a markup shock, or an oil price shock, will have similar implications for the term premium.

A final point to note is that, not only does our simple model predict a term premium that is positive on average, it also implies that the term premium is countercyclical - that is, all three shocks in Figure 2 cause the term premium to rise at the same time that they cause consumption to fall-consistent with a widely-held view in the macro-finance literature that risk premiums should be and are higher in recessions (e.g., Campbell and Cochrane, 1999, Cochrane, 2007, Piazzesi and Swanson, 2008). Thus, not only is the term premium in our model large and variable, it is consistent with this key business-cycle correlation.

\subsection{Time-Varying Term Premiums and Heteroskedasticity}

Epstein-Zin preferences not only improve the model's ability to match the level of the term premium, they also greatly improve the model's ability to generate a term premium that varies over time. For the case of expected utility, the term premium in the model varies by less than one-tenth of one basis point, and this result is extremely robust to varying the model's parameters over wide ranges. In contrast, our baseline Epstein-Zin specification produces a term premium with an unconditional standard deviation of 5.3 basis points, and the "best fit" parameterization does even better, generating a term premium with an 18.4 basis point standard deviation.

In order for the model to generate appreciable time-variation in the term premium, how-

\footnotetext{
${ }^{29}$ Note that this analysis is for long-term nominal bonds rather than real bonds. If real interest rates are lower in recessions, then the traditional line of reasoning still implies that the real yield curve should slope downward. In fact, the evidence in Evans (1998) and Appendix B of Piazzesi and Schneider (2006) suggests that this is the case.
} 
ever, either the stochastic discount factor or the asset return, or both, must display conditional heteroskedasticity. ${ }^{30}$ In our model, the exogenous driving shocks (technology, government purchases, monetary policy) are all homoskedastic, but our DSGE model endogenously generates conditional heteroskedasticity in the stochastic discount factor and other variables. Intuitively, a second- or higher-order solution to the stochastic discount factor and other variables in the DSGE model includes terms of the form $x_{t-1} \varepsilon_{t}$, the product of a state variable and a shock, and the conditional variance of these terms varies with the state of the economy $x$.

With expected utility preferences, second-order terms and the conditional heteroskedasticity generated by the model are small. But with Epstein-Zin preferences, the size of these secondand higher-order terms is much greater and leads to substantial endogenously-generated heteroskedasticity in the stochastic discount factor. For example, in the expected utility version of the model, the standard deviation of one-step-ahead innovations to the stochastic discount factor is 0.33 percent on average and ranges from 0.30 to 0.36 percent depending on the state of the economy. ${ }^{31}$ But for the baseline Epstein-Zin version of our model, the stochastic discount factor has a one-step-ahead standard deviation of 7.11 percent and ranges from 5.23 to 8.99 percent, a much greater variability as well as much higher average level. This enormous increase in the heteroskedasticity of the stochastic discount factor helps to explain how the Epstein-Zin version of our model is able to generate a term premium that varies substantially over time. ${ }^{32}$

From equations (6) and (15), the stochastic discount factor in the model is given by:

$$
m_{t+1} \equiv \beta\left(\frac{c_{t+1}}{c_{t}}\right)^{-\gamma}\left(\frac{V_{t+1}}{\left(E_{t} V_{t+1}^{1-\alpha}\right)^{1 /(1-\alpha)}}\right)^{-\alpha} \frac{1}{\pi_{t+1}} .
$$

Although consumption growth and inflation in the model exhibit a slight degree of heteroskedasticity due to the presence of higher-order terms, by far the largest source of heteroskedasticity in (42) is the term involving $V$. Intuitively, a negative technology shock in our model causes

\footnotetext{
30 To see this, note that one measure of the risk premium on an asset is $E_{t}\left(m_{t+1} p_{t+1}\right)-e^{-i_{t}} p_{t+1}=$ $\operatorname{Cov}_{t}\left(m_{t+1}, p_{t+1}\right)$, the time- $t$ price of the asset less the risk-neutral price. If the stochastic discount factor and asset price are both conditionally homoskedastic, then so is the conditional covariance and hence the risk premium.

31 As discussed above, the one-step-ahead standard deviation of the stochastic discount factor depends on the state of the economy. Since we know the unconditional variances and covariances of the state variables in our model, we can use these to derive the unconditional variance of the one-step-ahead standard deviation of the stochastic discount factor. The square root of that number is about .0145 percent. Multiplying by \pm 2 gives a range of \pm .029 percent. The one-step-ahead standard deviation of the stochastic discount factor will lie within this range about $95 \%$ of the time.

32 The long-term bond price is also heteroskedastic in the model, but only slightly so. The primary driver of time-varying term premia in the model is heteroskedasticity in the stochastic discount factor.
} 
consumption to fall by more than output, because investment and government purchases in the model are fixed (this is one of the nonhomotheticities of the model). Technology shocks, which are multiplicative with respect to output, thus have an increasingly large effect on consumption as output and consumption decline. As a result, the effective quantity of consumption risk faced by households in the model rises as the state of the economy worsens. The one-step-ahead variance of $V$ thus increases as the state of the economy worsens, and risk premia are larger. This volatility and endogenous heteroskedasticity of $V$ are then amplified by a factor of about 75 in equation (42) because of the additional coefficient $-\alpha=73$.

\section{Long-Run Risk}

The preceding section demonstrates that Epstein-Zin preferences can match both the basic macroeconomic and financial moments in a DSGE framework. This success stands in sharp contrast to habit-based specifications, which Jermann (1998), Lettau and Uhlig (2000), and Rudebusch and Swanson (2008) found failed in the DSGE setting despite their successes in endowment economy studies such as Campbell and Cochrane (1999) and Wachter (2006). However, the fit in the last two columns of Table 2 comes at the cost of a high value for the quasi-CRRA in the model. In this section, we examine to what extent a long-run risk in the model (such as long-run inflation risk or long-run productivity risk) can help the model fit the data with less reliance on a high quasi-CRRA.

\subsection{Long-Run Inflation Risk}

Since Bansal and Yaron (2004), the finance literature has stressed the importance of long-run risk in consumption growth. In contrast, there has been little attention devoted to long-run nominal risks in the economy, specifically, time-variation in the economy's long-run inflation rate, even though such risk would be very relevant for pricing nominal bonds. We therefore consider the case where the monetary authority's target rate of inflation, $\pi_{t}^{*}$, varies over time. Certainly, financial market perceptions of the long-run inflation rate in the United States appear to have varied considerably in recent decades: Kozicki and Tinsley (2001) show that survey data on long-run inflation expectations have varied substantially over the past 50 years, Rudebusch and 
$\mathrm{Wu}(2007,2008)$ estimate a similar degree of variation in a macro-finance no-arbitrage model, and Gürkaynak, Sack, and Swanson (2005) find that the "excess sensitivity" of long-term bond yields to macroeconomic announcements is consistent with financial markets perceiving the long-run inflation rate in the economy to be less than perfectly anchored.

From the point of view of modeling the term premium, long-run inflation risk has a number of advantages over long-run consumption risk. First, estimates of the low-frequency component of consumption are extremely imprecise, so it is very difficult to test empirically the direct predictions of a Bansal-Yaron long-run consumption risk model with observable macroeconomic variables. In contrast, survey data on long-run inflation expectations are readily available and show considerable variation. Second, the idea that long-term nominal bonds are risky because of uncertainty about future monetary policy and long-run inflation is intuitively appealing. Third, estimates of the term premium in the finance literature are low in the 1960s, high in the late 1970s and early 1980s, and then low again in the 1990s and 2000s (e.g., Kim and Wright, 2005), which suggests that inflation and inflation variability are highly correlated with the term premium, at least over these longer, decadal samples. Modeling the linkage between long-run inflation risk and the term premium thus seems to be a promising avenue for understanding and modeling long-term bond yields.

Following the empirical evidence in Gürkaynak et al. (2005),we assume that $\pi_{t}^{*}$ loads to some extent on the recent history of inflation:

$$
\pi_{t}^{*}=\rho_{\pi^{*}} \pi_{t-1}^{*}+\vartheta_{\pi^{*}}\left(\bar{\pi}_{t}-\pi_{t}^{*}\right)+\varepsilon_{t}^{\pi^{*}} .
$$

There are two main advantages to using specification (43) rather than a simple random walk or $\operatorname{AR}(1)$ specification with $\vartheta_{\pi^{*}}=0$. First, (43) allows long-term inflation expectations to respond to current news about inflation and economic activity in a manner that is consistent with the bond market responses documented by Gürkaynak et al. Thus, $\vartheta_{\pi^{*}}>0$ seems to be consistent with the data. ${ }^{33}$ Second, if $\vartheta_{\pi^{*}}=0$, then even though $\pi_{t}^{*}$ varies over time, it does not do so systematically with output or consumption; as a result, long-term bonds are not particularly risky, in the sense that their returns are not very correlated with the household's stochastic discount factor. In fact, long-term bonds even have some elements of insurance in this case, because a negative shock to $\varepsilon_{t}^{\pi^{*}}$ leads the monetary authority to raise interest rates and depress

\footnotetext{
${ }^{33}$ Gürkaynak et al. find that a value of $\vartheta_{\pi^{*}}=.02$ is roughly consistent with the bond market data.
} 
output at the same time that it causes long-term bond yields to fall and bond prices to rise, which results in a negative term premium on the bond. By contrast, if $\vartheta_{\pi^{*}}>0$, then a negative technology shock today raises inflation and long-term inflation expectations and depresses bond prices at exactly the same time that it depresses output, which makes holding long-term bonds quite risky and helps the model to match the positive mean term premium we see in the data.

We add equation (43) to our DSGE model from the preceding section, setting the baseline value of $\vartheta_{\pi^{*}}=.02$, which is consistent with the high-frequency bond market evidence in Gürkaynak et al. (2005). We set the baseline values for $\rho_{\pi^{*}}$ and $\sigma_{\pi^{*}}$ equal to .99 and 5 basis points, respectively, consistent with the Bayesian DSGE model estimates in Levin et al. (2005).

As can be seen in Figure 1, the effects of the long-run inflation risk on the term premium are indeed substantial. As the quasi-CRRA is varied along the horizontal axis, holding the other parameters of the model fixed at their baseline values, the term premium is always the highest for the version of the model with long-run inflation risk. That is, by making long-term bonds in the model riskier, the model can generate any given level of the term premium with a lower value for the quasi-CRRA than was possible without long-run inflation risk.

Table 3 reports the macroeconomic and financial moments that result from introducing longrun inflation risk into our DSGE model. The first column repeats the empirical moments from the U.S. data, and the second column reports results for a version of the model with long-run inflation risk and expected utility preferences (that is, with the parameters of the model set to their baseline values, except for $\alpha=0$ ). The introduction of time-variation in $\pi^{*}$ makes the macroeconomic variables a little more volatile on average, but the fit of the model to the macro data is about as good overall as for the baseline model. The fit of the model to the financial moments, however, is also no better - the term premium is still less than one basis point, and its variation is still only about one-tenth of one basis point, far smaller than the data (and this result is extremely robust to varying the parameters of the model over wide ranges). Intuitively, long-run inflation risk increases the quantity of nominal bond risk in the model, but households simply aren't risk-averse enough for that greater quantity of risk to have a noticeable effect on bond prices in the model.

With Epstein-Zin preferences, however, introducing long-run inflation risk into the model has substantial effects. The third column of Table 3 reports results for the model with Epstein- 
Table 3

Empirical and Model-Based Unconditional Moments with Long-Run Risk

Model with Model with Model with

\begin{tabular}{ccccc} 
Unconditional & U.S. Data, & EU Preferences & EZ Preferences & EZ Preferences \\
Moment & $1961-2007$ & and LR $\pi^{*}$ Risk & and LR $\pi^{*}$ Risk & and LR $A^{*}$ Risk \\
\hline
\end{tabular}

\begin{tabular}{|c|c|c|c|c|}
\hline $\operatorname{sd}[C]$ & 1.19 & 1.70 & 2.01 & 2.37 \\
\hline $\operatorname{sd}[L]$ & 1.71 & 3.02 & 1.37 & 2.13 \\
\hline $\operatorname{sd}\left[w^{r}\right]$ & 0.82 & 2.40 & 1.52 & 1.81 \\
\hline $\operatorname{sd}[\pi]$ & 2.52 & 3.65 & 3.25 & 2.95 \\
\hline $\operatorname{sd}[i]$ & 2.71 & 3.32 & 2.94 & 2.86 \\
\hline $\operatorname{sd}[r]$ & 2.30 & 2.39 & 1.71 & 1.55 \\
\hline $\operatorname{sd}\left[i^{(40)}\right]$ & 2.41 & 1.71 & 1.89 & 1.66 \\
\hline $\operatorname{mean}\left[\psi^{(40)}\right]$ & 1.06 & .003 & 1.05 & 0.98 \\
\hline $\operatorname{sd}\left[\psi^{(40)}\right]$ & 0.54 & .001 & 0.51 & 0.28 \\
\hline $\operatorname{mean}\left[i^{(40)}-i\right]$ & 1.43 & -.10 & 0.96 & 0.89 \\
\hline $\operatorname{sd}\left[i^{(40)}-i\right]$ & 1.33 & 1.73 & 1.10 & 1.36 \\
\hline $\operatorname{mean}\left[x^{(40)}\right]$ & 1.76 & .003 & 1.04 & 0.96 \\
\hline $\operatorname{sd}\left[x^{(40)}\right]$ & 23.43 & 13.07 & 11.64 & 12.20 \\
\hline \multicolumn{5}{|l|}{ distance to: } \\
\hline macro moments & & 6.62 & 2.48 & 3.88 \\
\hline finance moments & & 7.80 & 2.18 & 2.27 \\
\hline all moments & & 14.42 & 4.67 & 6.15 \\
\hline \multicolumn{5}{|l|}{ memo: } \\
\hline quasi-CRRA & & 2 & 90 & 90 \\
\hline IES & & 0.5 & 1.1 & 0.5 \\
\hline$\chi$ & & 1.5 & 0.5 & 1.5 \\
\hline$\xi$ & & 0.75 & 0.65 & 0.8 \\
\hline$\rho_{A}$ & & .9 & .95 & - \\
\hline$\sigma_{A}$ & & .01 & .005 & .001 \\
\hline$\rho_{\pi^{*}}$ & & .99 & .99 & - \\
\hline$\vartheta_{\pi^{*}}$ & & .02 & .015 & - \\
\hline$\sigma_{\pi^{*}}$ & & $5 \mathrm{bp}$ & $1 b p$ & - \\
\hline$\rho_{A^{*}}$ & & - & - & .97 \\
\hline$\sigma_{A^{*}}$ & & - & - & .005 \\
\hline
\end{tabular}

All variables are quarterly values expressed in percent. Inflation and interest rates, the term premium $(\psi)$, and excess holding period returns $(x)$ are expressed at an annual rate. 
Zin preferences and long-run inflation risk, where we have searched over values for $\rho_{\pi^{*}}, \vartheta_{\pi^{*}}$, and $\sigma_{\pi^{*}}$ as well as the quasi-CRRA, IES, $\chi, \xi, \rho_{A}$, and $\sigma_{A}$ to find the best fit to the empirical moments in the first column. ${ }^{34}$ Relative to the the second column, the term premium and other financial moments generated by the model are much larger and much more in line with the data. Relative to the case of no long-run risk - the last column of Table 2 - the term premium is far more variable once long-term inflation risk is incorporated into the model. ${ }^{35}$ Intuitively, when $\vartheta_{\pi^{*}}>0$, technology (and other) shocks have an ever more persistent effect on inflation because of the pass-through from $\pi_{t}$ to $\pi_{t}^{*}$, which makes long-term nominal bonds in the model even more risky. As a result, the term premium in the model is larger and more volatile.

The estimation achieves this improvement in fit by choosing a high value for the quasi-CRRA, which helps to fit the term premium and other financial moments with relatively moderate consumption volatility. (Alternatively, the model with long-run inflation risk can fit the macro and financial moments just as well as the model without long-run risk, using a lower value for the quasi-CRRA). The time-variation in $\pi^{*}$ makes the model as a whole more volatile, so the estimation compensates for this by choosing a lower technology shock variance, $\sigma_{A}=.005$; the greater degree of nominal volatility in the model due to time-varying $\pi^{*}$, together with the smaller degree of real volatility due to technology shocks, improves the overall fit of the model to the macro moments. The estimation also prefers a higher value for the IES, 1.1, which helps shift some of the volatility of consumption over to short-term real interest rates, in line with the data, and a low value for $\chi$ (a high Frisch elasticity of labor supply), which helps shift some of the volatility of real wages over to labor. Finally, a low value for $\sigma_{\pi^{*}}$ fits the data the best-as discussed above, exogenous shocks to $\pi^{*}$ actually imply a lower term premium, all else equal, because long-term nominal bonds in the model act like insurance against this particular type of shock. It is the loading $\vartheta_{\pi^{*}}$ of $\pi^{*}$ on current inflation that makes time-variation in $\pi^{*}$ costly in the model, not exogenous shocks to $\pi^{*}$.

\footnotetext{
${ }^{34}$ In addition to the range of parameter values considered in the previous section, we searched over values of $\rho_{\pi^{*}} \in\{.98, .99, .995, .997, .998\}, \vartheta_{\pi^{*}} \in\{0, .005, .01, .015, .02\}$, and $\sigma_{\pi^{*}} \in\{1,2, \ldots, 15\}$ basis points.

35 These results hold for a ten-year zero-coupon bond in the model as well: the term premium has a mean of $76.2 \mathrm{bp}$ and a standard deviation of $39.7 \mathrm{bp}$. These are a few basis points less than for the consol, but the main points in the text are all unchanged.
} 


\subsection{Long-Run Productivity Risk}

Finally, we investigate to what extent a long-run real risk could help to explain the financial market moments in our model with less reliance on a high value for the quasi-CRRA. Bansal and Yaron (2004) found that a relatively small but highly persistent long-run risk to consumption can account for a variety of risk premium puzzles in an endowment economy framework. In our DSGE setting, consumption is not an exogenous process, but we can model long-run real risk in the economy as a long-run risk to productivity. Analogous to Bansal and Yaron, we thus assume that the level of aggregate technology $A$ has a small but highly persistent component $A^{*}$ as well as an i.i.d. component:

$$
\begin{gathered}
\log A_{t}^{*}=\rho_{A^{*}} \log A_{t-1}^{*}+\varepsilon_{t}^{A^{*}}, \\
\log A_{t}=\log A_{t}^{*}+\varepsilon_{t}^{A}
\end{gathered}
$$

where the shocks $\varepsilon_{t}^{A^{*}}$ and $\varepsilon_{t}^{A}$ are uncorrelated white noise. ${ }^{36}$ We then replace equation (17) of our DSGE model with (44) and (45), holding $\pi^{*}$ fixed for simplicity, and search over the values of $\rho_{A^{*}}, \sigma_{A^{*}}$, and $\sigma_{A}$ (as well as the quasi-CRRA, IES, $\chi$, and $\xi$ ) that fit the data the best. ${ }^{37}$

The final column of Table 3 reports the results from incorporating this long-run risk into our DSGE model. The model with long-run productivity risk does not fit the empirical macroeconomic moments as well as the model with long-run inflation risk, but the fit to the financial moments is about as good. Relative to the model without long-run risk - the last column of Table 2 - the fit to the macroeconomic variables is slightly better overall and the fit to the financial moments is improved, particularly for the standard deviations of the term premium and excess holding period return. As in the model without long-run risk, the estimation chooses a high value for the quasi-CRRA, 90, and low value for the IES, 0.5. The long-run risk itself is chosen to be only moderately persistent, $\rho_{A^{*}}=.97$, which fits the macroeconomic data better than a combination of a large i.i.d. technology shock together with a small but extremely persistent process for $A^{*}$.

\footnotetext{
36 See also Croce (2008). Bansal and Yaron (2004) and Croce use a difference-stationary process to represent long-run risk, while we use a very persistent but stationary process; thus, our specification here may understate the importance of long-run risks relative to those authors. Using a difference-stationary process for technology would require us to make major modifications to our baseline model specification (e.g. by changing the utility kernel), which would make comparing the results to the standard New Keynesian DSGE literature (e.g. Woodford, 2003) difficult. We thus leave this avenue for future research.

37 In addition to the range of parameter values considered in Section 3, we searched over values of $\rho_{A} \in$ $\{.95, .96, .97, .98, .99, .995, .997\}$, values for $\sigma_{A^{*}}$ between .0001 and .007 , and values for $\sigma_{A}$ between 0 and .03 .
} 


\section{Conclusions}

In stark contrast to our earlier work with habits (Rudebusch and Swanson, 2008), here we have found that introducing Epstein-Zin preferences into a DSGE model is a very successful strategy for matching both the basic macroeconomic and financial moments in the data. We are able to obtain a large and volatile term premium in an otherwise standard, structural DSGE model, thus generalizing the earlier endowment economy results in finance. Our model offers a structural explanation for why the yield curve slopes upward (technology-type shocks that cause inflation and output to move in opposite directions), and endogenously generates conditional heteroskedasticity in the stochastic discount factor - and hence a time-varying risk premiumwithout relying on exogenous conditional heteroskedasticity in the driving shocks. Introducing long-run risks into the model allows us to fit the data with a lower value for the quasi-CRRA, or to fit the data even better for a given level of the quasi-CRRA.

Of course, many unresolved issues remain for exploration. Although we have restricted attention in this paper to a simple, stylized DSGE model along the lines of Woodford (2003), there is no reason why the methods of this paper cannot be applied to larger, more empirically relevant DSGE models such as Christiano, Eichenbaum, and Evans (2005) and Smets and Wouters (2003); indeed, preliminary research that we have conducted indicates that all of the basic conclusions in the present paper carry over to these larger-scale and more fully-specified models. A related next step would go beyond matching sample moments and perform full econometric estimation (and inference) of a DSGE model with Epstein-Zin preferences, as in van Binsbergen, et al. (2008), but extended to include intrinsic nominal rigidities and endogenous inflation. Examining to what extent a DSGE model can jointly explain the risk premiums on equity, real bonds, nominal bonds, and uncovered interest parity violations would also be very interesting. Finally, the relationship between the variability or uncertainty surrounding the central bank's inflation objective and the size and variability of the term premium warrants further study, in our view. In short, there appear to be many fruitful avenues for future research in this area. 


\section{Appendix: Equations of the Model}

The following equations show exactly how we incorporate Epstein-Zin preferences into our otherwise standard DSGE model in first-order recursive form, and how bond prices and the term premium are computed in the model. The Mathematica-style syntax of these equations is consistent with the perturbation AIM algorithm of Swanson et al. (2006), which we use to solve this system to third order around the nonstochastic steady state.

(* Value function and Euler equation *)

$\mathrm{V}[\mathrm{t}]==\mathrm{C}[\mathrm{t}] \wedge(1$-gamma $) /(1$-gamma $)-\operatorname{chi0} * \mathrm{~L}[\mathrm{t}]^{\wedge}(1+\operatorname{chi}) /(1+\operatorname{chi})+$ beta $* \mathrm{Vkp}[\mathrm{t}]$,

$\mathrm{C}[\mathrm{t}]{ }^{\wedge}$-gamma $==\operatorname{beta} *(\operatorname{Exp}[\operatorname{Int}[\mathrm{t}]] / \mathrm{pi}[\mathrm{t}+1]) * \mathrm{C}[\mathrm{t}+1]^{\wedge}$-gamma $*(\mathrm{Vkp}[\mathrm{t}] / \mathrm{V}[\mathrm{t}+1]) \wedge$ alpha,

(* The following two equations define the E-Z-W-K-P certainty equivalent term $\mathrm{Vkp}[\mathrm{t}]=\left(\mathrm{E}_{-} \mathrm{t} \mathrm{V}[\mathrm{t}+1]^{\wedge}(1 \text {-alpha })\right)^{\wedge}(1 /(1$-alpha $))$. It takes two equations to do this because perturbation AIM sets the expected value of all equations equal to zero, E_t $\mathrm{F}$ (variables) $=0$. Thus, the first equation below defines Valphaexp[t] $==\mathrm{E} \_\mathrm{t} V[\mathrm{t}+1]^{\wedge}(1$-alpha). The second equation then takes the (1-alpha)th root of this expectation.

Note: the literature often refers to 1 - (1-alpha)(1-gamma) as the CRRA, but that terminology is only justifiable when the model has one state variable (wealth) and the model is homothetic. The present model does not satisfy either of these conditions. Nevertheless, alpha is one measure of risk aversion, as shown by Epstein and Zin.

Finally, the scaling and unscaling of Valphaexp[t] by the constant VAIMSS improves the numerical behavior of the model; without it, the steady-state value of Valphaexp can be minuscule (e.g., 10^-50), which requires Mathematica to use astronomical levels of precision in order to solve. *)

Valphaexp $[\mathrm{t}]==(\mathrm{V}[\mathrm{t}+1] / \mathrm{VAIMSS}) \wedge(1$-alpha $)$,

$\operatorname{Vkp}[\mathrm{t}]==\operatorname{VAIMSS} *$ Valphaexp $[\mathrm{t}]^{\wedge}(1 /(1$-alpha $))$,

(* Price-setting equations *)

$\mathrm{zn}[\mathrm{t}]==(1+$ theta $) * \mathrm{MC}[\mathrm{t}] * \mathrm{Y}[\mathrm{t}]+\mathrm{xi} *$ beta $*(\mathrm{C}[\mathrm{t}+1] / \mathrm{C}[\mathrm{t}])^{\wedge}$-gamma $*(\mathrm{Vkp}[\mathrm{t}] / \mathrm{V}[\mathrm{t}+1])^{\wedge}$ alpha $*_{\mathrm{pi}}[\mathrm{t}+1]^{\wedge}((1+$ theta $) /$ theta/eta $) *_{\mathrm{zn}}[\mathrm{t}+1]$,

$\mathrm{zd}[\mathrm{t}]==\mathrm{Y}[\mathrm{t}]+\mathrm{xi} *$ beta $*(\mathrm{C}[\mathrm{t}+1] / \mathrm{C}[\mathrm{t}])^{\wedge}$-gamma $*(\mathrm{Vkp}[\mathrm{t}] / \mathrm{V}[\mathrm{t}+1])^{\wedge}$ alpha $* \mathrm{pi}[\mathrm{t}+1]^{\wedge}(1 /$ theta $)$ $*_{\mathrm{zd}}[\mathrm{t}+1]$,

$\mathrm{p} 0[\mathrm{t}]^{\wedge}(1+(1+$ theta $) /$ theta $*(1$-eta $) /$ eta $)==\mathrm{zn}[\mathrm{t}] / \mathrm{zd}[\mathrm{t}]$

$\mathrm{pi}[\mathrm{t}]^{\wedge}(-1 /$ theta $)==(1-\mathrm{xi}) *\left(\mathrm{p} 0[\mathrm{t}]^{*} \mathrm{pi}[\mathrm{t}]\right)^{\wedge}(-1 /$ theta $)+\mathrm{xi}$,

(* Marginal cost and real wage $\left.{ }^{*}\right)$

$\mathrm{MC}[\mathrm{t}]==\operatorname{wreal}[\mathrm{t}] /$ eta $^{*} \mathrm{Y}[\mathrm{t}]^{\wedge}((1-$ eta $) /$ eta $) / \mathrm{A}[\mathrm{t}]^{\wedge}(1 /$ eta $) / \mathrm{KBar}^{\wedge}((1-$ eta $) /$ eta $)$, $\operatorname{chi0} *^{*} \mathrm{~L}[\mathrm{t}] \wedge \operatorname{chi} / \mathrm{C}[\mathrm{t}]^{\wedge}-$ gamma $==\operatorname{wreal}[\mathrm{t}],\left({ }^{*}\right.$ no adj costs $\left.*\right)$ 
(* Output equations *)

$\mathrm{Y}[\mathrm{t}]==\mathrm{A}[\mathrm{t}] * \mathrm{KBar}^{\wedge}(1-\mathrm{eta}) * \mathrm{~L}[\mathrm{t}] \wedge$ eta $/ \operatorname{Disp}[\mathrm{t}]$,

$\operatorname{Disp}[\mathrm{t}]^{\wedge}(1 /$ eta $)==(1-\mathrm{xi}) * \mathrm{p} 0[\mathrm{t}]^{\wedge}(-(1+$ theta $) /$ theta/eta $)$

$+\mathrm{xi} * \mathrm{pi}[\mathrm{t}]{ }^{\wedge}((1+$ theta $) /$ theta/eta $) * \operatorname{Disp}[\mathrm{t}-1]^{\wedge}(1 /$ eta $)$,

$\mathrm{C}[\mathrm{t}]==\mathrm{Y}[\mathrm{t}]-\mathrm{G}[\mathrm{t}]-$ IBar, $(*$ aggregate resource constraint, no adj costs $*)$

(* Monetary Policy Rule *)

$\operatorname{piavg}[\mathrm{t}]==$ rhoinflavg $*$ piavg $[\mathrm{t}-1]+(1-$ rhoinflavg $) *$ pi $[\mathrm{t}]$,

$4 * \operatorname{Int}[\mathrm{t}]==(1$-taylrho $) *(4 * \log [1 /$ beta $]+4 * \log [\operatorname{piavg}[\mathrm{t}]]$

$+\operatorname{taylpi} *(4 * \log [\operatorname{piavg}[\mathrm{t}]]-\operatorname{pistar}[\mathrm{t}])+\operatorname{tayly} *(\mathrm{Y}[\mathrm{t}]-\mathrm{YBar}) / \mathrm{YBar})$

+ taylrho $* 4 * \operatorname{Int}[\mathrm{t}-1]+\operatorname{eps}[\operatorname{Int}][\mathrm{t}],\left(*\right.$ multiply Int, infl by 4 to put at annual rate $\left.{ }^{*}\right)$

(* Exogenous Shocks *)

$\log [\mathrm{A}[\mathrm{t}] / \mathrm{ABar}]==\operatorname{rhoa} * \log [\mathrm{A}[\mathrm{t}-1] / \mathrm{ABar}]+\operatorname{eps}[\mathrm{A}][\mathrm{t}]$,

$\log [\mathrm{G}[\mathrm{t}] / \mathrm{GBar}]==\operatorname{rhog} * \log [\mathrm{G}[\mathrm{t}-1] / \mathrm{GBar}]+\operatorname{eps}[\mathrm{G}][\mathrm{t}]$,

$\operatorname{pistar}[\mathrm{t}]==(1-\mathrm{rhopistar}) *$ piBar $+\operatorname{rhopistar} * \operatorname{pistar}[\mathrm{t}-1]+\operatorname{gssload} *(4 * \log [\operatorname{piavg}[\mathrm{t}]]-\operatorname{pistar}[\mathrm{t}])$

$+\operatorname{eps}[\operatorname{pistar}][\mathrm{t}]$,

(* Term premium and other auxiliary finance equations $*$ )

$\operatorname{Intr}[\mathrm{t}]==\log [\operatorname{Exp}[\operatorname{Int}[\mathrm{t}-1]] / \mathrm{pi}[\mathrm{t}]],\left(*\right.$ ex post real short rate $\left.{ }^{*}\right)$

pricebond $[\mathrm{t}]==1+$ consoldelta $*$ beta $*(\mathrm{C}[\mathrm{t}+1] / \mathrm{C}[\mathrm{t}])^{\wedge}$-gamma $*(\mathrm{Vkp}[\mathrm{t}] / \mathrm{V}[\mathrm{t}+1]) \wedge$ alpha $/ \mathrm{pi}[\mathrm{t}+1]$

*pricebond $[\mathrm{t}+1]$,

pricebondrn $[\mathrm{t}]==1+$ consoldelta $*$ pricebondrn $[\mathrm{t}+1] / \operatorname{Exp}[\operatorname{Int}[\mathrm{t}]]$,

$\operatorname{ytm}[\mathrm{t}]==\log [\operatorname{consoldelta} *$ pricebond $[\mathrm{t}] /($ pricebond $[\mathrm{t}]-1)] * 400,(*$ yield in annualized pct $*)$

$\operatorname{ytmrn}[\mathrm{t}]==\log [$ consoldelta*pricebondrn $[\mathrm{t}] /(\operatorname{pricebondrn}[\mathrm{t}]-1)] * 400$,

termprem $[\mathrm{t}]==100 *(\mathrm{ytm}[\mathrm{t}]-\mathrm{ytmrn}[\mathrm{t}]),\left(*\right.$ term prem in annualized basis points $\left.{ }^{*}\right)$

$\operatorname{ehpr}[\mathrm{t}]==(($ consoldelta $*$ pricebond $[\mathrm{t}]+\operatorname{Exp}[\operatorname{Int}[\mathrm{t}-1]]) / \operatorname{pricebond}[\mathrm{t}-1]-\operatorname{Exp}[\operatorname{Int}[\mathrm{t}-1]]) * 400$,

slope $[\mathrm{t}]==\mathrm{ytm}[\mathrm{t}]-\operatorname{Int}[\mathrm{t}] * 400$ 


\section{References}

[1] Altig, David, Lawrence Christiano, Martin Eichenbaum, and Jesper Lindé (2004). "FirmSpecific Capital, Nominal Rigidities, and the Business Cycle," unpublished manuscript, Northwestern University.

[2] Backus, David, Allan Gregory, and Stanley Zin (1989). "Risk Premiums in the Term Structure," Journal of Monetary Economics 24, 371-99.

[3] Backus, David, Bryan Routledge, and Stanley Zin (2007). "Asset Prices in Business Cycle Analysis," unpublished manuscript, Columbia Business School.

[4] Bansal, Ravi and Ivan Shaliastovich (2007). "Risk and Return in Bond, Currency, and Equity Markets," unpublished manuscript, Duke University.

[5] Bansal, Ravi and Amir Yaron (2004). "Risks for the Long Run: A Potential Resolution of Asset Pricing Puzzles," Journal of Finance 59, 1481-1509.

[6] Barillas, Francisco, Lars Hansen, and Thomas Sargent (2008). "Doubts or Variability?" unpublished manuscript, University of Chicago.

[7] Boldrin, Michele, Lawrence Christiano, and Jonas Fisher (2001). "Habit Persistence, Asset Returns, and the Business Cycle," American Economic Review 91, 149-66.

[8] Campbell, John and John Cochrane (1999). "By Force of Habit: A Consumption-Based Explanation of Aggregate Stock Market Behavior," Journal of Political Economy 107, 20551.

[9] Campbell, John and Robert Shiller (1991). "Yield Spreads and Interest Rate Movements: A Bird's Eye View," Review of Economic Studies 58, 495-514.

[10] Carrillo, Julio, Patrick Fève, and Julien Matheron (2007). "Monetary Policy Inertia or Persistent Shocks: A DSGE Analysis," International Journal of Central Banking 3, 1-38.

[11] Christiano, Lawrence, Martin Eichenbaum, and Charles Evans (2005). "Nominal Rigidities and the Dynamic Effects of a Shock to Monetary Policy," Journal of Political Economy $113,1-45$.

[12] Cochrane, John (2007). "Financial Markets and the Real Economy," in Handbook of the Equity Risk Premium, ed. Rajnish Mehra, Amsterdam: Elsevier, 237-330.

[13] Cochrane, John and Monika Piazzesi (2005). "Bond Risk Premia," American Economic Review 95, 138-60.

[14] Croce, Mariano (2008). "Long-Run Productivity Risk: A New Hope for Production-Based Asset Pricing," unpublished manuscript, Kenan-Flagler Business School.

[15] Den Haan, Wouter (1995). "The Term Structure of Interest Rates in Real and Monetary Economies," Journal of Economic Dynamics and Control 19, 909-40. 
[16] Epstein, Lawrence and Stanley Zin (1989). "Substitution, Risk Aversion and the Temporal Behavior of Consumption and Asset Returns: A Theoretical Framework." Econometrica $57,937-69$.

[17] Evans, Martin (1998). "Real Rates, Expected Inflation, and Inflation Risk Premia," Journal of Finance 53, 187-218.

[18] Gürkaynak, Refet, Brian Sack, and Eric Swanson (2005). "The Sensitivity of Long-Term Interest Rates to Economic News: Evidence and Implications for Macroeconomic Models," American Economic Review 95, 425-36.

[19] Gürkaynak, Refet, Brian Sack, and Jonathan Wright (2007). "The U.S. Treasury Yield Curve: 1961 to the Present," Journal of Monetary Economics 54, 2291-2304.

[20] Hall, Robert (1988). "Intertemporal Substitution in Consumption," Journal of Political Economy 96, 339-57.

[21] Jermann, Urban (1998). "Asset Pricing in Production Economies," Journal of Monetary Economics 41, 257-75.

[22] Kihlstrom, Richard and Leonard Mirman (1974). "Risk Aversion with Many Commodities," Journal of Economic Theory 8, 361-88.

[23] Kim, Don and Jonathan Wright (2005). "An Arbitrage-Free Three-Factor Term Structure Model and the Recent Behavior of Long-Term Yields and Distant-Horizon Forward Rates," Federal Reserve Board Finance and Economics Discussion Series 2005-33.

[24] Kozicki, Sharon and Peter Tinsley (2001). "Shifting Endpoints in the Term Structure of Interest Rates," Journal of Monetary Economics 47, 613-52.

[25] Kreps, David and Evan Porteus (1978). "Temporal Resolution of Uncertainty and Dynamic Choice Theory," Econometrica 46, 185-200.

[26] Lettau, Martin and Harald Uhlig (2000). "Can Habit Formation Be Reconciled with Business Cycle Facts?" Review of Economic Dynamics 3, 79-99.

[27] Levin, Andrew, Alexei Onatski, John C. Williams, and Noah Williams (2005). "Monetary Policy Under Uncertainty in Micro-Founded Macroeconometric Models," NBER Macro Annual 20, 229-87.

[28] Malloy, Christopher, Tobias Moskowitz, and Annette Vissing-Jorgensen (2008). "Long-Run Stockholder Consumption Risk and Asset Returns," Journal of Finance, forthcoming.

[29] Mehra, Rajnish and Edward Prescott (1985). "The Equity Premium: A Puzzle," Journal of Monetary Economics 15, 145-61.

[30] Piazzesi, Monika and Martin Schneider (2006). "Equilibrium Yield Curves," NBER Macro Annual 21, 389-442.

[31] Piazzesi, Monika and Eric Swanson (2008). "Futures Prices as Risk-Adjusted Forecasts of Monetary Policy," Journal of Monetary Economics 55, 677-91. 
[32] Pistaferri, Luigi (2003). "Anticipated and Unanticipated Wage Changes, Wage Risk, and Intertemporal Labor Supply," Journal of Labor Economics 21.

[33] Rudebusch, Glenn D., (2002). "Term Structure Evidence on Interest Rate Smoothing and Monetary Policy Inertia." Journal of Monetary Economics 49, 1161-87.

[34] Rudebusch, Glenn D., (2006). "Monetary Policy Inertia: Fact or Fiction?" International Journal of Central Banking 2, 85-135.

[35] Rudebusch, Glenn D., Brian Sack, and Eric Swanson (2007). "Macroeconomic Implications of Changes in the Term Premium," Federal Reserve Bank of St. Louis, Review 89, 241-69.

[36] Rudebusch, Glenn D. and Eric Swanson (2008). "Examining the Bond Premium Puzzle with a DSGE Model," Journal of Monetary Economics, forthcoming.

[37] Rudebusch, Glenn D. and Tao Wu (2007). "Accounting for a Shift in Term Structure Behavior with No-Arbitrage and Macro-Finance Models," Journal of Money, Credit, and Banking 39 (2-3), March, 395-422.

[38] Rudebusch, Glenn D. and Tao Wu (2008). "A Macro-Finance Model of the Term Structure, Monetary Policy, and the Economy," Economic Journal 118, July 2008, 906-26.

[39] Smets, Frank, and Raf Wouters (2003). "An Estimated Stochastic Dynamic General Equilibrium Model of the Euro Area," Journal of European Economic Association 1, 1123-75.

[40] Swanson, Eric, Gary Anderson, and Andrew Levin (2006). "Higher-Order Perturbation Solutions to Dynamic, Discrete-Time Rational Expectations Models," Federal Reserve Bank of San Francisco Working Paper 2006-01.

[41] Tallarini, Thomas (2000). "Risk-Sensitive Real Business Cycles," Journal of Monetary Economics 45, 507-32.

[42] Van Binsbergen, Jules, Jesus Fernández-Villaverde, Ralph Koijen, and Juan Rubio-Ramírez (2008). "Working with Epstein-Zin Preferences: Computation and Likelihood Estimation of DSGE Models with Recursive Preferences," unpublished manuscript, University of Pennsylvania.

[43] Vissing-Jorgensen, Annette (2002). "Limited Asset Market Participation and the Elasticity of Intertemporal Substitution," Journal of Political Economy 110, 825-53.

[44] Wachter, Jessica (2006). "A Consumption-Based Model of the Term Structure of Interest Rates," Journal of Financial Economics 79, 365-99.

[45] Weil, Phillipe (1989). "The Equity Premium Puzzle and the Risk-Free Rate Puzzle," Journal of Monetary Economics 24, 401-21.

[46] Woodford, Michael (2003). Interest and Prices: Foundations of a Theory of Monetary Policy, Princeton University Press. 


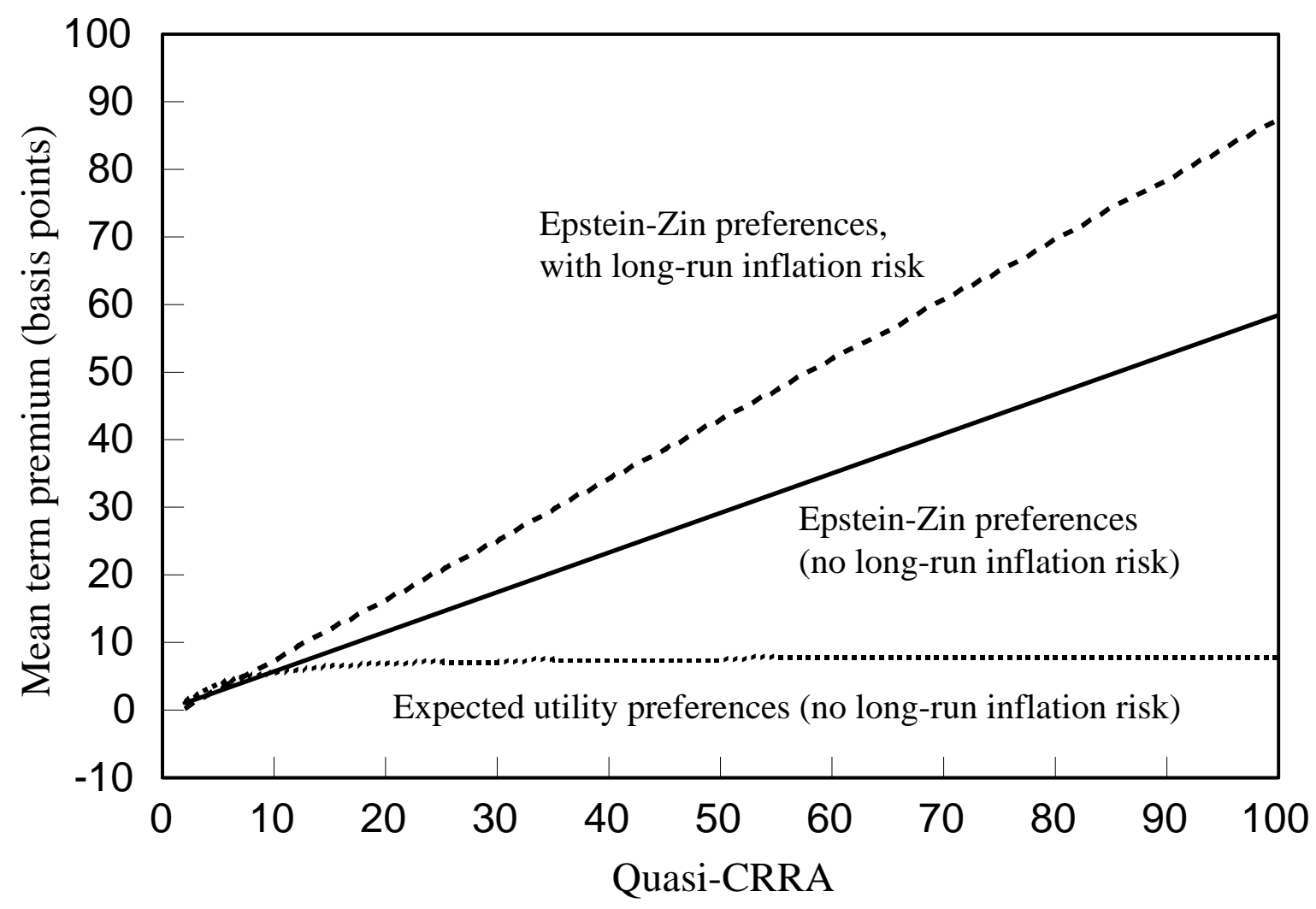

Figure 1. Mean term premium with varying amounts of risk aversion.

The solid and dashed lines show the mean 10-year term premium in a DSGE model without and with long-run inflation risk, respectively. The dotted line shows the mean term premium in the version of the model with expected utility preferences. 
Response to Technology Shock
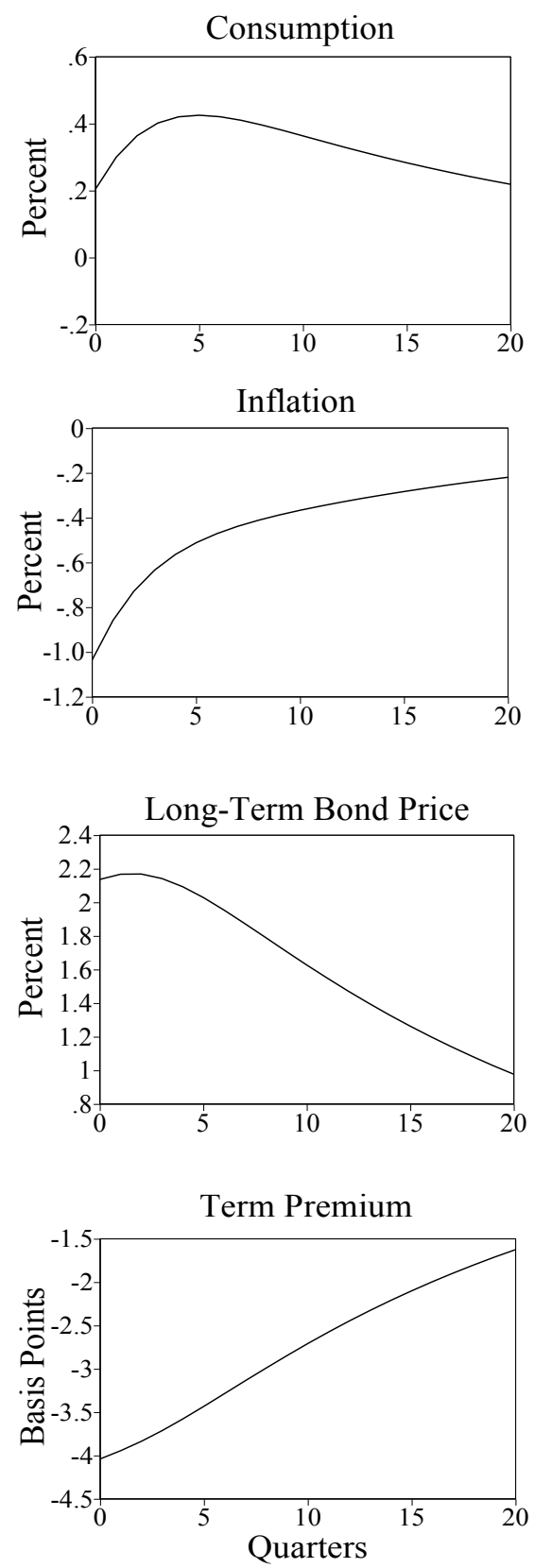

Response to Government Spending Shock
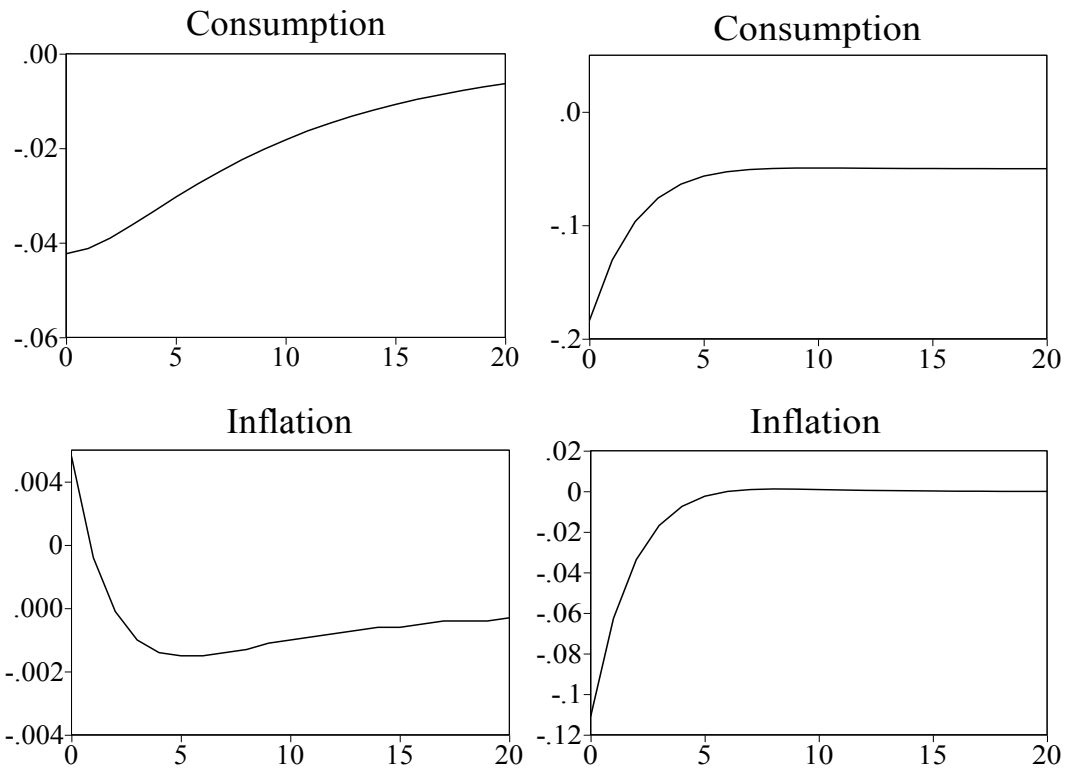

Policy Shock
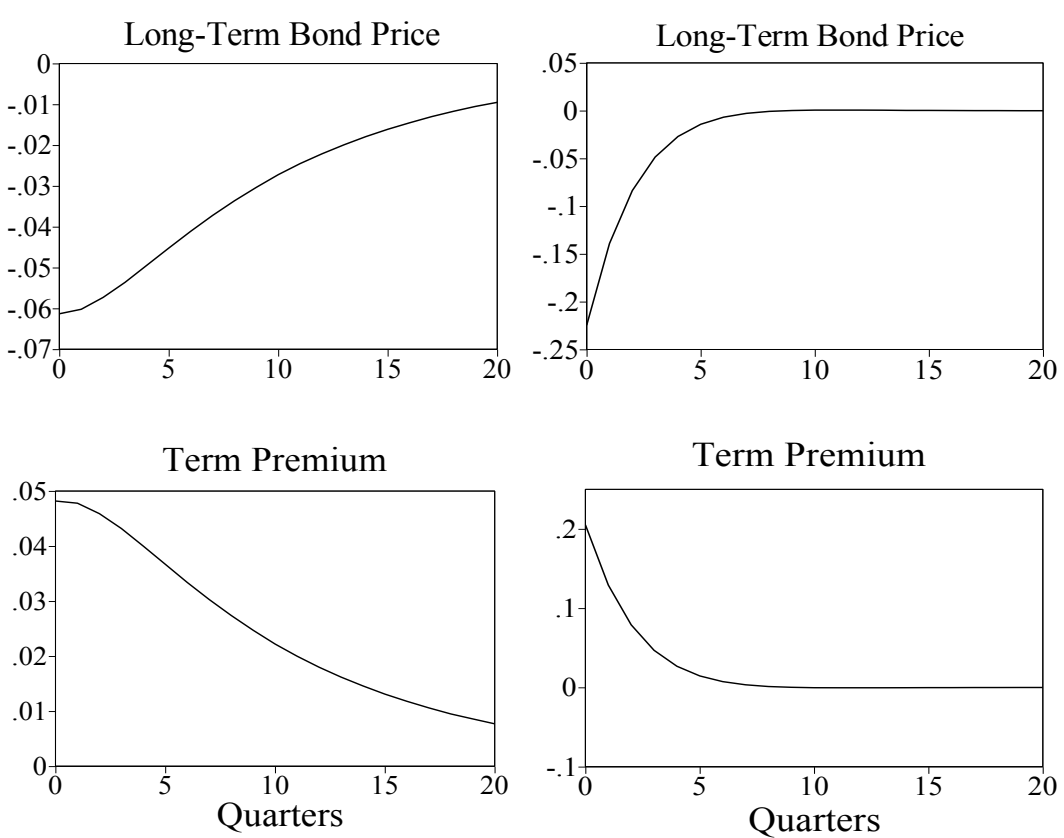

Term Premium

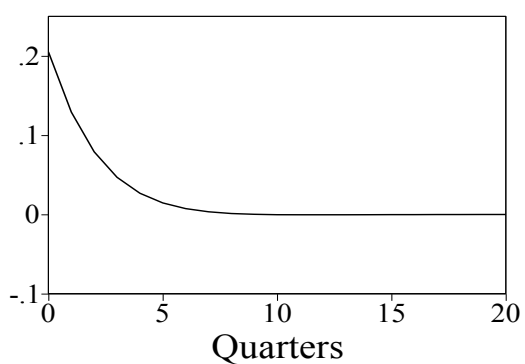

Figure 2. Impulse responses to structural shocks.

Impulse responses of consumption, inflation, long-term bond prices, and term premiums to positive one standard deviation shocks to technology, government spending, and monetary policy. 